Review

\title{
Review of Integrated Optical Biosensors for Point-of-Care Applications
}

\author{
Yung-Tsan Chen ${ }^{1}$, Ya-Chu Lee ${ }^{1}$, Yao-Hsuan Lai ${ }^{1}$, Jin-Chun Lim ${ }^{1}$, Nien-Tsu Huang ${ }^{2,3}{ }^{\circ}$, \\ Chih-Ting Lin ${ }^{2,3,4}$ and Jian-Jang Huang $1,2, *(\mathbb{B}$
}

1 Graduate Institute of Photonics and Optoelectronics, National Taiwan University, No. 1, Sec. 4, Roosevelt Road, Taipei 106, Taiwan; d03941013@ntu.edu.tw (Y.-T.C.); r08941047@ntu.edu.tw (Y.-C.L.); r07941068@ntu.edu.tw (Y.-H.L.); r07941106@ntu.edu.tw (J.-C.L.)

2 Department of Electrical Engineering, National Taiwan University, No. 1, Sec. 4, Roosevelt Road, Taipei 106, Taiwan; nthuang@ntu.edu.tw (N.-T.H.); timlin@ntu.edu.tw (C.-T.L.)

3 Graduate Institute of Biomedical Electronics and Bioinformatics, National Taiwan University, No. 1, Sec. 4, Roosevelt Road, Taipei 106, Taiwan

4 Graduate Institute of Electronics Engineering, National Taiwan University, No. 1, Sec. 4, Roosevelt Road, Taipei 106, Taiwan

* Correspondence: jjhuang@ntu.edu.tw

Received: 23 November 2020; Accepted: 16 December 2020; Published: 18 December 2020

check for updates

\begin{abstract}
This article reviews optical biosensors and their integration with microfluidic channels. The integrated biosensors have the advantages of higher accuracy and sensitivity because they can simultaneously monitor two or more parameters. They can further incorporate many functionalities such as electrical control and signal readout monolithically in a single semiconductor chip, making them ideal candidates for point-of-care testing. In this article, we discuss the applications by specifically looking into point-of-care testing (POCT) using integrated optical sensors. The requirement and future perspective of integrated optical biosensors for POC is addressed.
\end{abstract}

Keywords: optical biosensors; point-of-care; integration

\section{Introduction}

A biosensor is an analytical device that is composed of a bioreceptor, a transducer, and a signal processor for detecting biological substances and monitoring biological interactions. The transduction methods for biosensing applications are mainly based on optical, physical, chemical, electrochemical, or mechanical properties of the functional biorecognition materials (e.g., enzyme, antibody, aptamer, and DNAzyme) [1-4]. The sensitivity and selectivity are two critical parameters in the development and application of biosensors. Among various types of sensors, optical biosensors offer great advantages over conventional analytical techniques because they enable direct, real-time, and label-free detection of many biological and chemical substances. Their advantages include high specificity, sensitivity, small size, and cost-effectiveness. The non-invasive optical detections have developed, in the past decade, from fluorescent spectroscopy to grating, SPR (surface plasmon resonance), SERS (surface-enhanced Raman scattering), GMR (guided mode resonance), etc. Fundamental light emission or light-matter interaction, such as fluorescent light emission from target analyte, optical diffraction due to light device structure interactions, and optical resonance within an optical cavity or designated structure, is employed by these optical sensing methods.

With the advance of clinical diagnostics, modern biosensing gradually evolves from off-site laboratory tests to near the patient on-site diagnosis [5-7]. The testing modality, referred to as point-of-care testing (POCT), emphasizes on less skilled labor involvement, easy-to-use, rapid diagnosis, 
and compact size at an affordable price [5-8]. Currently, POCT is available for a series of analyses by shrinking the instruments for the laboratory testing in size. For example, POCT is found for pregnancy testing, cardiometabolic testing, glucose testing, infectious disease testing (such as HIV, respiratory infection, and sexually transmitted diseases) and numerous other applications [8-13]. The above devices for point-of-care (POC) and those in development rely on various technologies. Integrated biosensors have the advantages of combining different test functionalities, miniaturization by embedding different sensor components, and integration with semiconductor fabrication process. For example, the lab-on-a-chip combines several analyses that are usually carried out in the laboratory into a single chip $[14,15]$. It represents a significant contribution toward POCT. The integration can be extended to other devices with different detection principles. Optical sensors integrated with microfluidic channels, electrical charge sensing, and mechanical sensing are particularly promising for next-generation POCT [16-22].

The present article provides an overview of recent advances in optical biosensors and their integration with microfluidic channels. The integrated biosensors provide two areas of advantage. First of all, by simultaneously monitoring two or more parameters, the accuracy and sensitivity of detecting target analytes are improved. Second, the integration, most of the time, shrinks the overall system by incorporating various components (including light source, transducer, detector, and reader) in the biosensor [23-25]. The sensor can further integrate many functionalities monolithically in a single chip by the semiconductor process. We hope the overview provides some hints for the interested readers to extend the applications of optical biosensors by considering many different sensing mechanisms. Finally, we discuss the applications by specifically looking into POCT using integrated optical sensors. The requirement and future perspective of integrated optical biosensors for POC is then addressed.

This article first classifies optical biosensors that are mostly discussed in the literature. These biosensors are fluorescence-based biosensors, SERS-based biosensors, grating and photonic crystal (PC) biosensors, GMR biosensors, and plasmon-based biosensors. The principle, design methodology, and biosensing applications are briefly introduced to provide readers the fundamental understanding of an optical biosensor. Although fiber based biosensing is also one of the most important sensing technologies, the fundamental principles usually derive from the aforementioned sensing approaches. Thus, fiber-based sensors are not covered in this paper. Interested readers can refer to some of the excellent reviews in this topic [26,27]. Because biosensing based on microfluidic platform allows simultaneous detection of physical, chemical, and mechanical properties of the solution, in Section 3, we review the integration of fluidic platforms with various optical biosensing technologies. Since not all integrated biosensors can be readily available for POCT, the requirement and classification of recent development are introduced in Session 4, along with a tabulated review of integrated biosensors for POCT.

\section{Classification of Optical Biosensors-Overview of the Principle and Applications}

\subsection{Fluorescence-Based Biosensors}

Fluorescence biosensors detect the concentration, location, and dynamics of biomolecules on the basis of the fluorescent phenomenon that occurs when electromagnetic radiation is absorbed by fluorophores or fluorescently labeled molecules so that the energy is converted into fluorescence emission (see Figure 1) [28-30]. A fluorescence biosensor includes the excitation light source (LEDs (light-emitting diodes), lasers), fluorophore molecules that label target biomolecules, and a photodetector that records the fluorescence intensity and spectrum. The fluorophore molecules can be small molecules, proteins, or quantum dots that are used to label proteins, nucleic acids, or lipids [31]. Generally, the excitation signal is biorecognized by the following techniques [32]: (1) FRET (Förster resonance energy transfer), (2) FLIM (fluorescence lifetime imaging), (3) FCS (fluorescence 
correlation spectroscopy), and (4) FI (changes in fluorescence intensity). In the next session, we review fluorescence-based biosensors integrated with microfluidic channels.

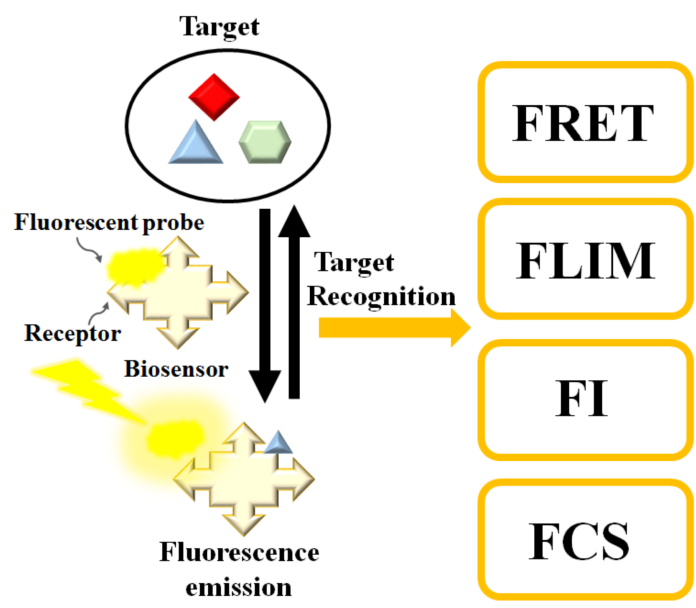

Figure 1. Schematic diagram of the fluorescence-based biosensor. Target analyte can be determined by FRET (Förster resonance energy transfer), FLIM (fluorescence lifetime imaging), FI (changes in fluorescence intensity), or FCS (fluorescence correlation spectroscopy).

\subsection{Surface-Enhanced Raman Scattering-Based Biosensors}

Raman scattering is an inelastic process when the kinetic energy of the incident photons is increased or decreased by interacting with molecular vibrations or rotations, phonons, or other excitations. The spectrum of the scattered photons indicates energy changes that are specific to the vibrational or rotational transitions modes of the molecular structure, which the biosensing of biomaterials is based upon. Because spontaneous (normal) Raman scattering is typically very weak, surface-enhanced Raman spectroscopy or surface-enhanced Raman scattering employs surface-sensitive techniques to enhance Raman scattering by molecules adsorbed on a specific medium or interface to improve the sensitivity $[33,34]$. The enhancement factors for SERS, as compared to normal Raman scattering, are attributed to two mechanisms - an electromagnetic mechanism and a chemical mechanism [35-38]. The electromagnetic enhancement is generally considered as a major factor of SERS enhancement. The effect of wavelength shift is contributed from the excitation of localized surface plasmon resonance (LSPR) [39] (see Figure 2). It is regarded as the oscillation of conduction electrons in noble metal nanoparticles, sharp metal tips, or roughened metal surfaces. LSPR is a short-range detection in the vicinity of the metal surface $(0-5 \mathrm{~nm}$ of the surface) $[39,40]$. The chemical mechanism depends not only on the substrate but also analyte molecules. It involves several different transitions/processes, which charge transfer between the energy levels of analyte molecules, with the fermi level of the substrate metal surface playing a critical role [41].

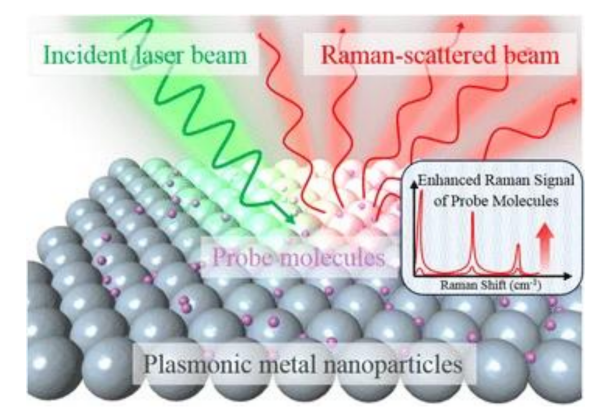

Figure 2. Schematic diagram of the SERS (surface-enhanced Raman scattering) process using metal nanoparticles to enhance the sensitivity [39]. Reproduced with permission from [39]. Copyright (2016) Springer Open. 
Recently, the studies on SERS biosensing have gradually migrated from probing single location of the plasmonic structure to detecting many spots through bioimaging with SERS tag [42,43]. In order to improve the electromagnetic enhancement factor, researchers have demonstrated various fabrication methods, such as adjusting the morphology, dielectric property, and interparticle distance of the plasmonic nanostructures [44,45].

\subsection{Photonic Crystal-Based Biosensors}

In PC structure, optical resonant modes or photonic bandgaps are created due to the periodic arrays of the refractive index. The periodic structure can be a Bragg reflector, one-dimensional (1D) slabs, or two-dimensional (2D) PC. An example of a PC biosensor is shown in Figure 3, where the resonant modes of the reflection spectrum are understood from the Bragg's law of diffraction. Since the resonant wavelength is sensitive to the refractive index of the materials on the PC structure, PC can be used for biosensing [46,47]. The narrow $(<1 \mathrm{~nm})$ bandwidth and high $(\approx 95-100 \%)$ reflectivity resonances enable PC biosensors for detecting small molecules, virus particles, DNA microarrays, and live cells [46-52].

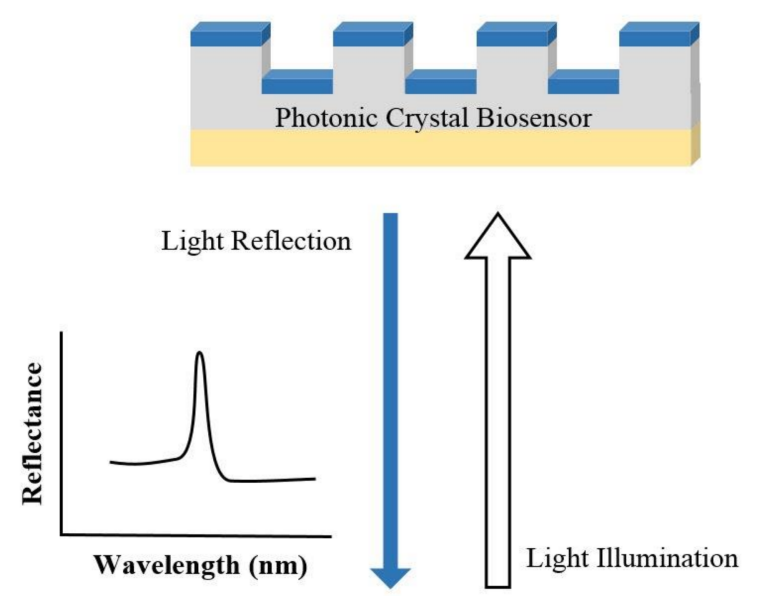

Figure 3. Illustration of the sensing mechanism of a photonic crystal (PC) biosensor.

Recent advances in PC biosensors are focused on optimizing the instrumentation and device structures. For example, PC fluorescence enhancement was utilized for high-sensitivity multiplexed cancer biomarker detection [53]. Moreover, on the basis of the PC surface mode detection, researchers have developed label-free flow multiplex sensing of cancer biomarkers [54].

\subsection{Guided Mode Resonance-Based Biosensor}

GMR is a resonance phenomenon occurred in the structure with an optical diffraction element and a waveguide layer. As shown in Figure 4, the guided modes are excited in the optical waveguide and are extracted to the air (reflectance $R_{0}, R_{1}, R_{2} \ldots$ and transmittance $T_{0}, T_{1}, T_{2}$. .) by interacting with the diffraction structure, resulting in a very narrow reflectance or transmittance resonant bandwidth [55-59]. The resonant peak is highly sensitive to the changes in surrounding refractive index, which is used in determining target analytes and the corresponding concentrations [58].

Recent advances in GMR sensor focus on the redesign of surface diffraction structure and improvement of sensitivity [60]. A "grating-waveguide" GMR sensor with coupled cross-stacked gratings was demonstrated to achieve a high wavelength and angular shift FOM (figure-of-merit) [61]. Moreover, an ultra-sensitive refractive index sensor employing phase detection in a GMR structure was also reported by incorporating the GMR structure in to a Mach-Zehnder interferometer. The researchers achieved a minimum phase shift of $\left(1.94 \times 10^{-3}\right) \pi$ that corresponded to a refractive index change of $3.43 \times 10^{-7}$ [58]. 


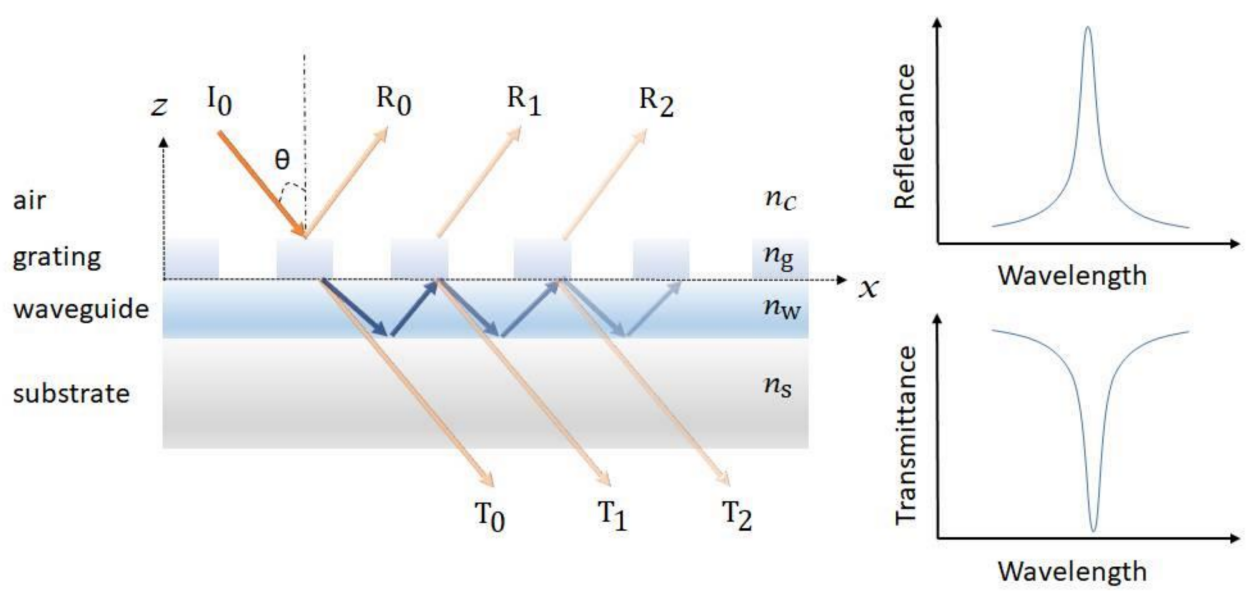

Figure 4. Schematic of a guided mode resonance (GMR) sensor. The resonance can be observed from both the reflectance and transmittance spectra.

\subsection{Plasmon-Based Biosensors}

The coupling of light with continuous metallic films (SPR (surface plasmon resonance)) or metallic nanoparticles (LSPR) produces strong confinement of electromagnetic field intensity. The confined field enhances the interaction between light and target molecules, resulting in the increase of sensitivity.

SPR is the resonant oscillation of conduction electrons at the interface between negative and positive permittivity material stimulated by incident light $[62,63]$. Figure 5 shows an example of a schematic configuration of an SPR biosensor. The incident light is totally internally reflected from the prism. The evanescent waves outside the prism interact with the plasma waves on the surface of the metal (typically Au or Ag) and induce plasmon resonance. SPR can be observed from the angle of minimum reflection (angle of maximum absorption), which is very sensitive to the refractive index of the biomaterial applied on the metal surface [63,64]. The method can be used to detect molecular adsorption, such as polymers, DNA, proteins, or molecular interactions [65-67].

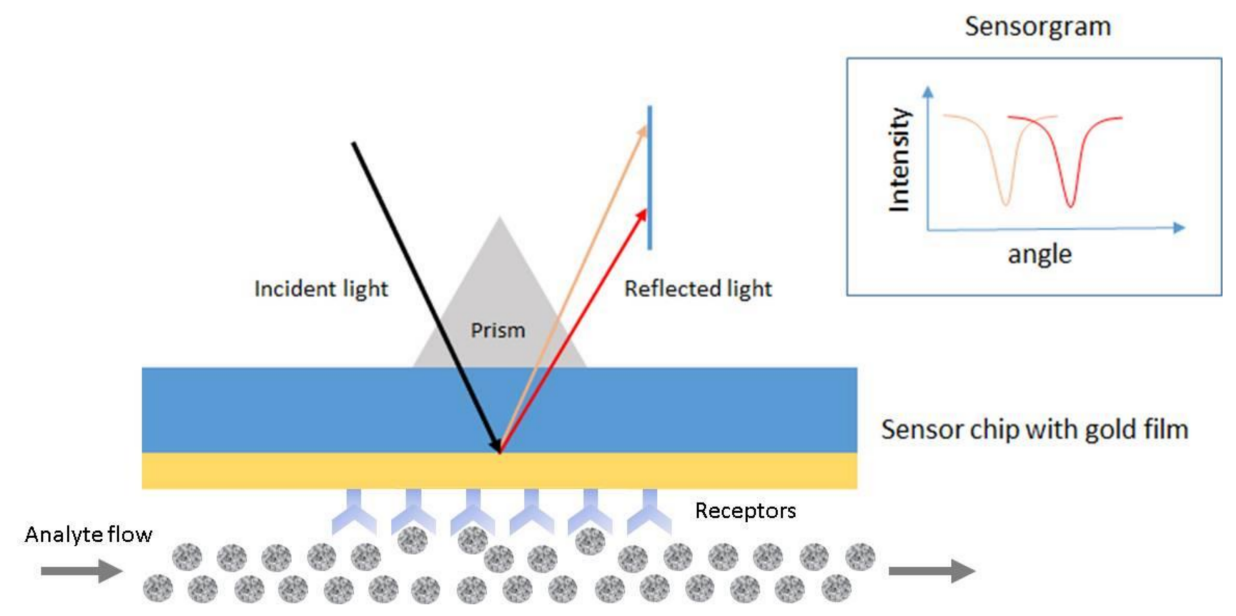

Figure 5. Schematic configuration of an surface plasmon resonance (SPR) biosensor.

LSPR is the plasmonic effect that occurs when the conducting electrons within the nanoparticles are excited and oscillated with the incident light, a phenomenon that is mentioned in Section 2.2. LSPR-based biosensor monitors the changes of plasmon frequency with the local refractive index of the target analyte in the near field of nanoparticles. The nano-sized sensor has the advantage of portability and miniaturization, as compared to the planar-type SPR sensor.

Up until now, it has still been challenging for plasmon-based biosensors to detect small molecules or very low concentration of analytes. To improve LOD (limit-of-detection), recent effects on the 
development of SPR biosensing have focused on choosing proper receptors and calibration strategy, while for LSPR, a combination of fluorescent quantum dots with plasmonic metal nanoparticles has been exploited [68]. In addition, Ewa Gorodkiewicz et al. has an excellent review paper on recent publications on SPR biosensors between 2016 and 2018 [69]. Depending on the maturity of development, the authors categorized SPR biosensors into five stages ranging from simple marker detection to clinical application of the previously developed biosensors. Instrumental solutions and details of biosensor construction were analyzed by including chips, receptors, and linkers.

\section{Methods of Integration with Optical Biosensors}

Optical biosensors embedded within the microfluidic channel is one of the most common approaches for biosensing applications. In this section, optical biosensors with microfluidic channels embedded in the sensor substrate are addressed. The main focus of the discussion is the microfluidics and how various optical biosensors are integrated.

\subsection{Microfluidics with Fluorescence Sensing}

Currently, major advancements in FRET, FLIM, FCS, and FI have revolutionized biology by increasing the resolution of optical microscopy, which provides non-invasive observation methods. Further integration with microfluidics allows precise manipulation of cells and proteins. Here, we describe some recent developments in these fields.

\subsubsection{Fluorescence Resonance Energy Transfer}

FRET relies on the transfer of excitation energy of a donor fluorophore to a nearby acceptor fluorophore through long-range dipole-dipole interactions. This occurs when the separating distance is within several nanometers. This technique has been widely used in the study of protein and DNA molecules [70,71]. More recently, Srisa-Art et al. used a microfluidic platform to perform binding assays and kinetics between streptavidin and biotin via FRET [72].

\subsubsection{Fluorescence Lifetime Imaging}

FLIM is a fluorescence imaging technique where the contrast is determined by differences in the excited state decay rate from a fluorescent sample. Robinson et al. demonstrated three-dimensional molecular imaging in a microfluidic mixer using fluorescent quenching [73] (Figure 6). More recent papers utilized FLIM for protein tracking and for the characterization of enhanced green fluorescent protein (EGFP) photoconversion [74].
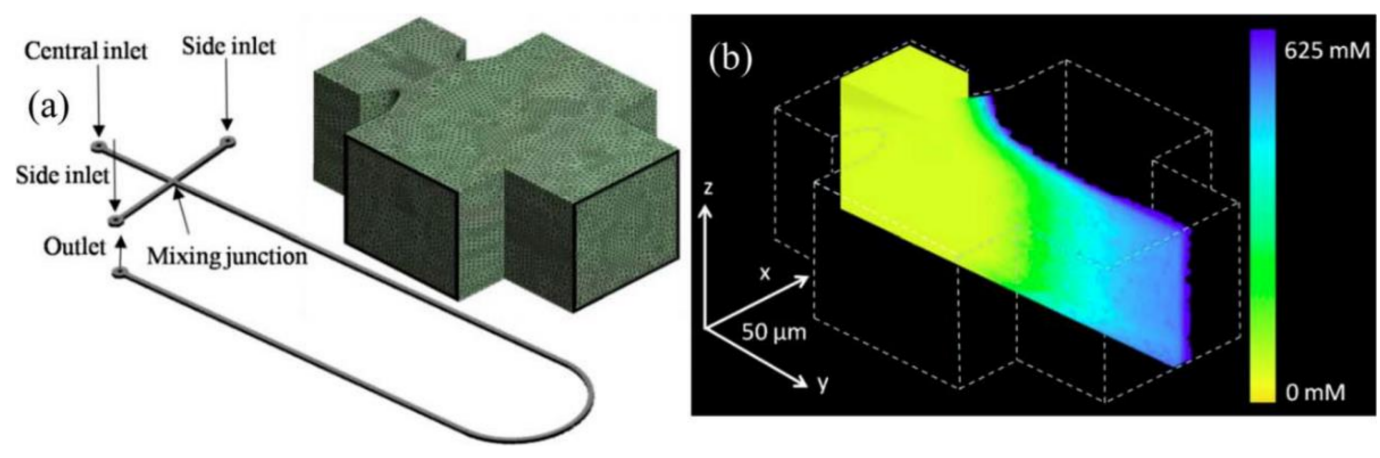

Figure 6. (a) Schematic of channel layout and (inset) computational fluid dynamics simulation (CFD) mesh of mixing junction. (b) 3D (three-dimensional) CFD simulation result of the mixing junction. Reproduced with permission from [73]. Copyright (2008) OSA publishing. 


\subsubsection{Fluorescence Correlation Spectroscopy}

An integrated microfluidic system can be used for high-sensitivity detection, as well as for sorting of fluorescent cells and particles [75]. Huang et al. integrated tunable nano-grating with a microfluidic channel to discriminate between green fluorescent protein (GFP) and calcein AM-stained HeyA8 cells (Figure 7A). Their system was able to differentiate between in-flow emission sources with only $5 \mathrm{~nm}$ peak-to-peak spectral differences and a significant intensity overlap at a confidence level as high as 85\% [76]. Another example was demonstrated by Baret et al., who used the oil-water interface to encapsulate fluorescent-labeled single cells in the microdroplet and utilized fluorescent-activated cell sorting manner to separate two different strains of Escherichia coli bacteria on the basis of enzymatic activity (Figure 7B) [77]. The sorting rate can be $\approx 300$ droplet $\mathrm{s}^{-1}$ with only $1 / 10,000$ false positive error.
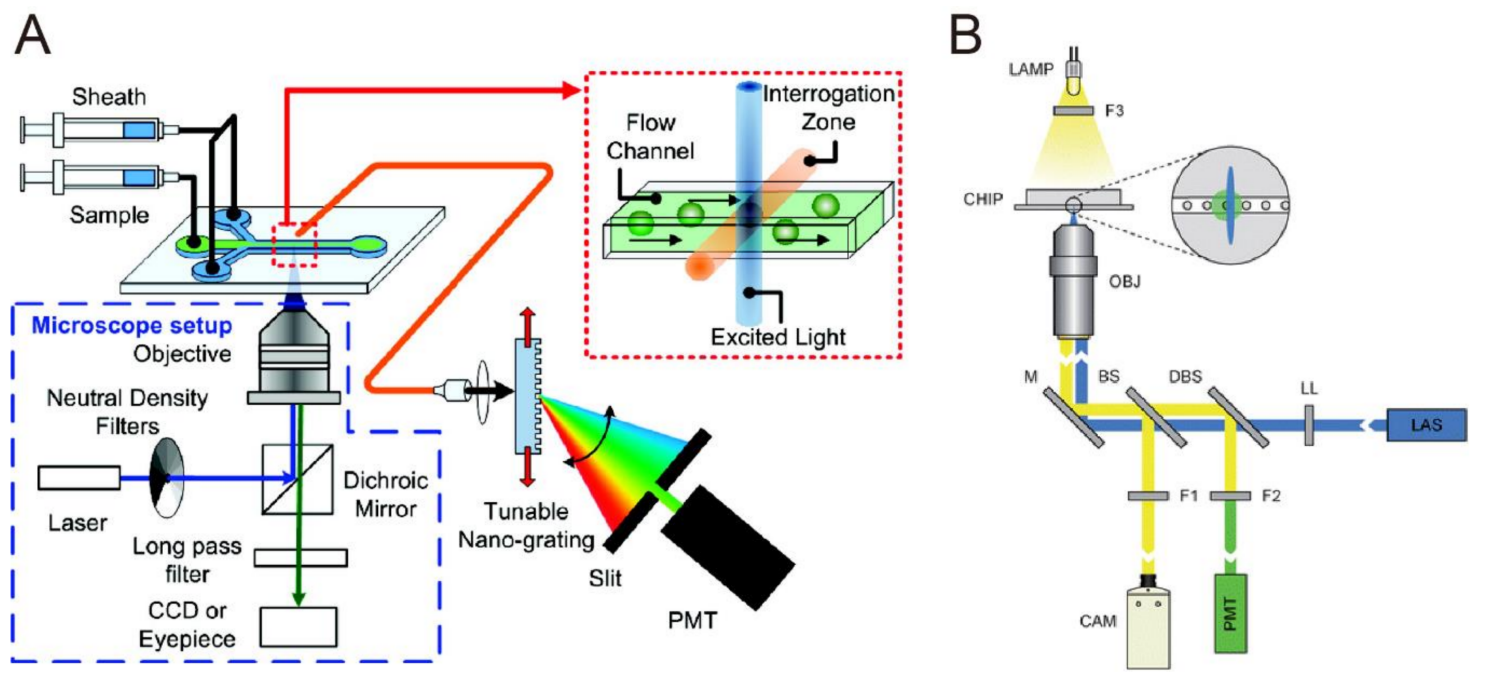

Figure 7. (A) Schematic of the microfluidic multispectral flow cytometry (MMFC) system. Reproduced with permission from [76]. Copyright (2010) ACS publications. (B) Schematic representation of the fluorescence-activated droplet sorting (FADS) system. Reproduced with permission from [77]. Copyright (2009) Royal Society of Chemistry.

\subsubsection{Fluorescence Intensity}

Yokokawa et al. integrated microfluidic channels with a total internal reflection (TIR) chip to observe fluorescent beads and insulin granules (Figure 8A). The SNR (signal-to-noise ratio) obtained was comparable to that of commercial TIRMF systems and was twice that of epifluorescence microscopy (EPIFM) [78]. Another example is demonstrated by Lai et al. and Huang et al. used optical fluorescence imagery to count cells trapped within microwell arrays, which allowed for automation of image processing (Figure 8B) [79].

Another example of integrating microfluidics with fluorescent sensing was demonstrated by Kumar et al., who developed a 3D-tapered metal-insulator-metal (MIM) waveguide device to greatly enhance fluorescence signal of biomolecules on the basis of surface plasmon polarization (SPP). By integrating microchannel to guide targeted biomolecules, the device allows for the detection of 10 pM immunoglobulin G (IgG), which can potentially be applied for complex molecules or even single-molecule detection [80]. 
A

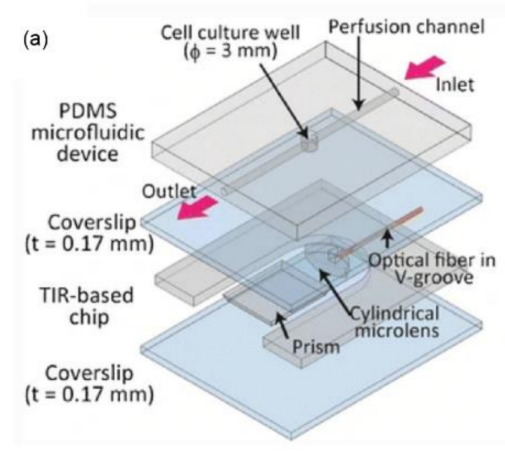

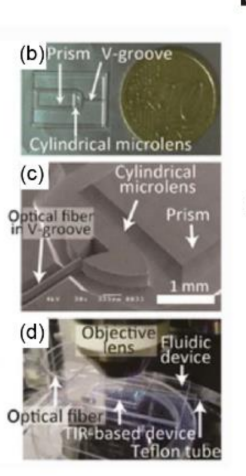

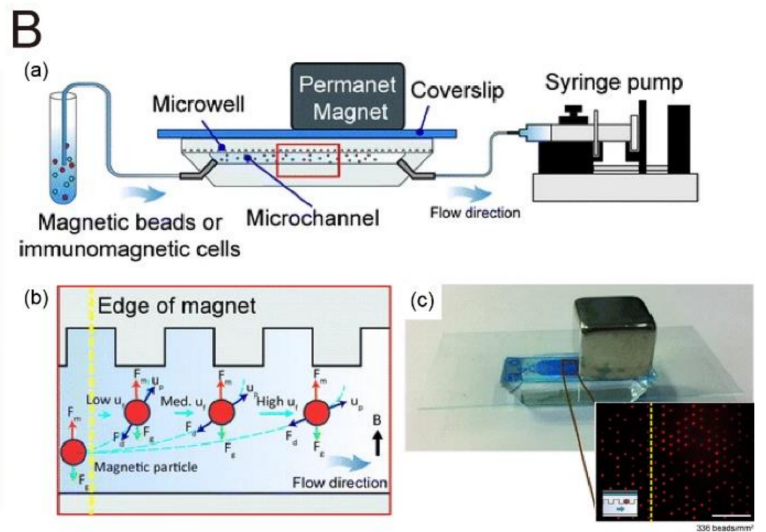

Figure 8. (A) The microfluidic device with on-chip total internal reflection fluorescence microscopy (TIRFM). Reproduced with permission from [78]. Copyright (2012) Springer. (B) A microfluidic microwell device for trapping fluorescent labeled single cells. Reproduced with permission from [79]. Copyright (2018) Springer.

\subsection{Microfluidics with SERS}

\subsubsection{Advantages of Integrating Microfluidics with Surface-Enhanced Raman Spectroscopy}

SERS has emerged as a powerful analytical technique in recent years, allowing rapid, label-free, non-invasive, and highly specific cell, microorganism, or chemical species or biomolecular identification. Although SERS is a highly specific detection method and is well suited for chemical issues, using SERS for practical sensing is still challenging as it requires tedious sample manipulation and sophisticated instrumentation due to the low sensitivity and low reproducibility of spectra [81]. SERS-based optofluidic integrated with microfluidics, which could deal with constrained small volume fluids, enabling fast and flexible sample treatments in a microchip, has the potential to improve the utility of the SERS effect in practical applications [82]. On-chip SERS detection with well-controlled flow conditions yields more reproducible results, and several problems—-for example, variable mixing times, variable scattering geometries, localized heating, and photo-dissociation-could be effectively solved. Integrating with microfluidics provides more consistent geometries and heat dissipation properties, which benefits photosensitive or heat-sensitive analytes [83].

\subsubsection{Microfluidics with Metallic Nanostructures for SERS Sensing}

Mao et al. fabricated a SERS sensor consisting of a PDMS (polydimethylsiloxane) microchannel cap and a nanopillar forest on the basis of a SERS-enhancement substrate (Figure 9) [84]. The nanopillar forest was obtained via a new oxygen-plasma-stripping procedure and consisted of Si pillars covered by a thin layer $(50 \mathrm{~nm})$ of sputtered Ag. The reproducibility of the measurements was improved considerably by the flow cell method, compared with the results obtained by the traditional drop-casting of an analyte solution onto the open metallic surface, and could greatly reduce relative measurement errors. The sensor showed much higher measurement repeatability than the open substrate, and it reduced the sample preparation time from several hours to a few minutes, which makes the device more reliable and facile for tracing chemical and biological analysis. 

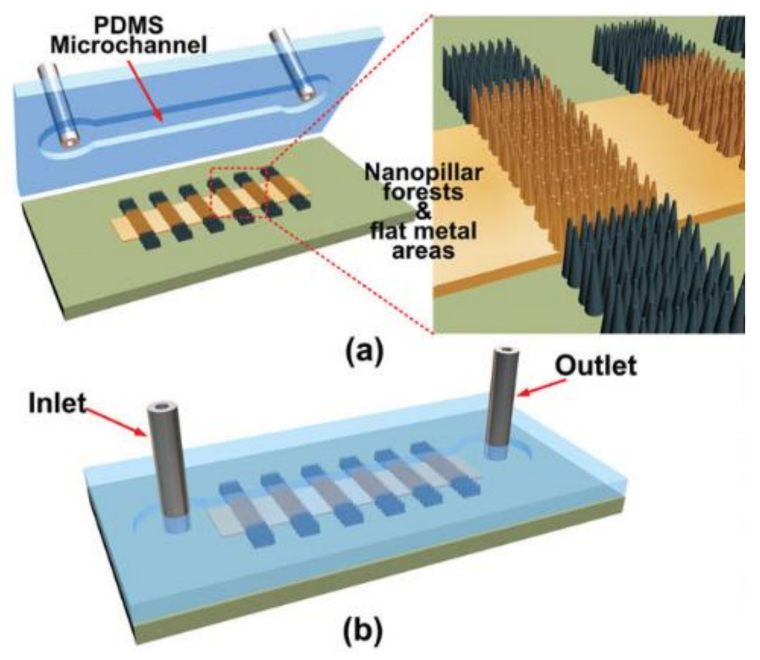

Figure 9. Schematic structures of the microfluidic SERS sensor: (a) schematic details on the SERS-active substrate with patterned nanopillar forests and flat metal areas for self-detection. (b) The overview of the microfluidic SERS sensor with tubes inserted as the inlet and outlet for analyte transportation. Reproduced with permission from [84]. Copyright (2014) Wiley-VCH Vertag.

Wang et al. developed a particle-based microfluidic molecular separation (PMMS) integrating SERS sensing platform (Figure 10), which could separate complicate molecule mixture and achieve in situ SERS detection [85]. The platform consists of an automatic microfluidic control system to precisely control the sample and reagent flow in the PMMS SERS device, composed of a $5 \mu \mathrm{m}$ particle-packed separation column followed by a two-dimensional Ag nanostructural substrate. This platform enables an automatic and sensitive purine derivatives analysis, which could be beneficial in applications requiring bacteria identification and quantification, such as environmental monitoring and drug development.

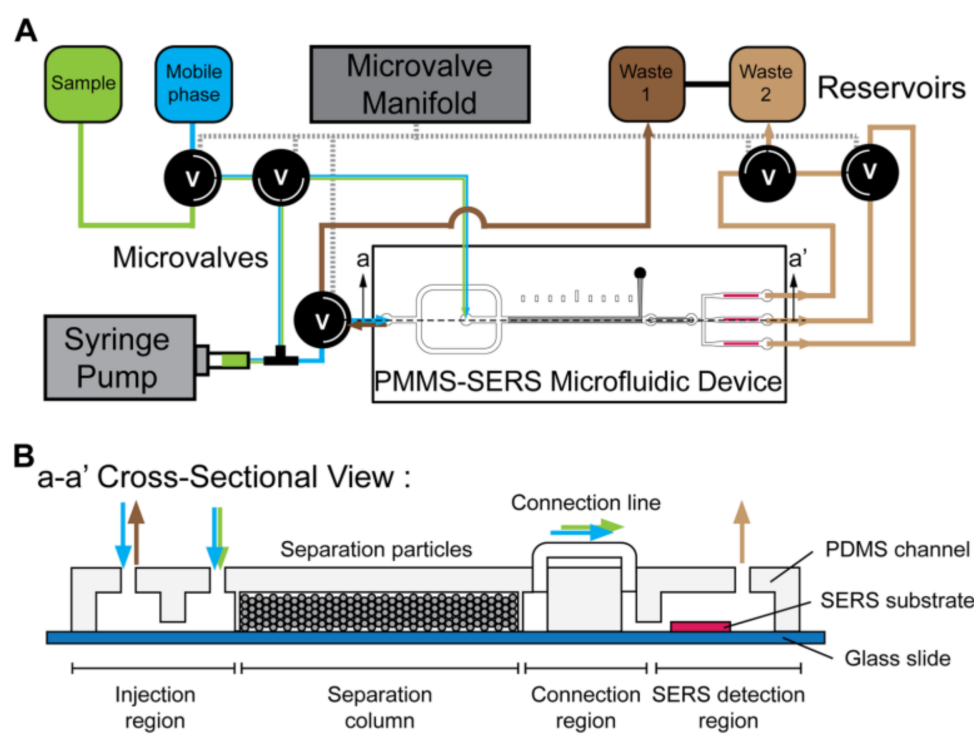

Figure 10. (A) Schematic diagram and (B) cross-section view of the particle-based microfluidic molecular separation (PMMS) SERS device. Reproduced with permission from [85]. Copyright (2019) Springer.

\subsubsection{Microfluidics with Metallic Colloidal Nanoparticles for SERS Sensing}

Besides integrating the SERS substrate with microfluidics, there is another way to create a SERS-sensing mechanism by simultaneously loading colloidal nanoparticles with analytes into the microchannel. For example, Hidi et al. developed a glass droplet-based microfluidic chip (Figure 11) for 
the detection of nitroxoline (NTX) in human urine samples [86]. Firstly, the Ag NPs and NTX solutions were pumped via port 1 and port 3, respectively. T-junction can generate droplets in the continuous phase of oil efficiently. Then, the aggregation agent, potassium chloride solution $(\mathrm{KCl})$, was injected into the already existing droplets via port 4 . The mixing of substances was assured by the meandering channels, while a long measurement loop allowed fine-tuning of the measurement position. In this way, the in-droplet concentration of the analytes could be easily and automatically adjusted. This platform allows for high-throughput and multiplex detection and can avoid cross-contamination of samples [87].

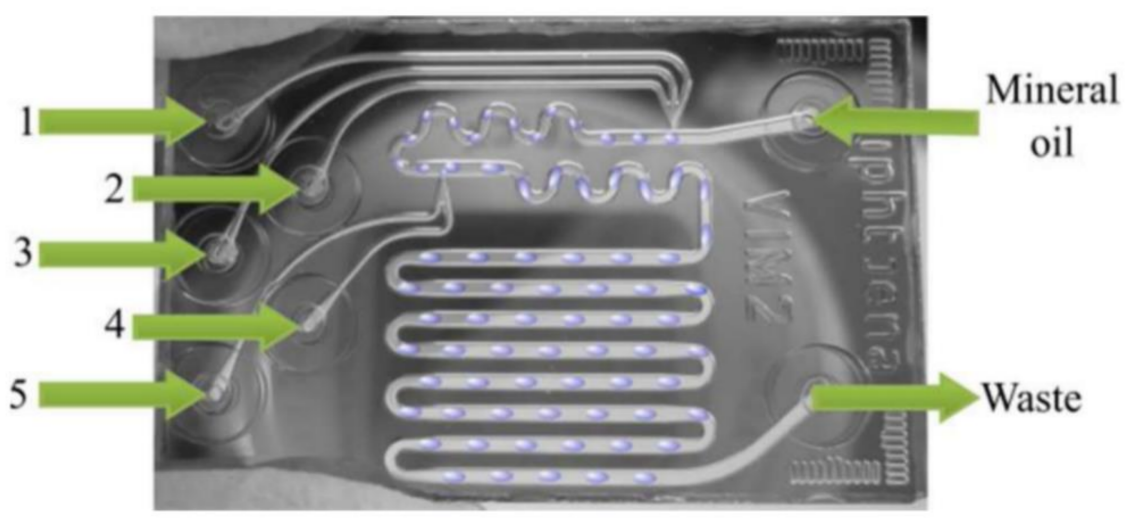

Figure 11. Droplet-based SERS microfluidics platform: ports 1-5 are used for the injection of sample, SERS-enhancement substrate, and their aggregation agent. Reproduced with permission from [86]. Copyright (2016) ACS publications.

Wu et al. developed a SERS-assisted 3D barcode microfluidic chip for a simultaneous, high-throughput, and multiplex immunoassay [88]. First, multiple proteins in different samples were spatially separated using a microfluidic patterned antibody substrate, forming a 2D hybridization array. Afterward, the mixture of SERS probes (Au and Ag nanorods) was flowed into the channel and captured by the corresponding antigens, forming a hybridization array used to identify and quantify the proteins. As different SERS probes were labeled with different Raman reporters, they were able to be employed as "SERS tags" to incorporate spectroscopic information into the 3D barcode. The microfluidic device with four reaction chambers was designed for the detection of the four different IgG biomarkers. Through integration with the microfluidics channel, one-step multiplex detection of human IgG, mouse IgG, and rabbit IgG within 30 min could be achieved with an ultra-sensitivity as low as $10 \mathrm{fg} \mathrm{mL}^{-1}$. Furthermore, in their later research [89], the authors successfully achieved multiplex detection of multiple breast cancer biomarkers, including carbohydrate antigen 15-3 (CA153), carbohydrate antigen 12-5 (CA125), and carcinoembryonic antigen (CEA) diagnosis. The system might be expected to provide multi-parallel high-throughput biomedical applications.

Although much work has been done to improve the mixing performance of the "injecting-nanoparticle" SERS microfluidic system, the external injection of nanoparticles seems a tedious process for microfluidic SERS applications. In addition, random colloidal nanoparticle aggregation is still a non-ignorable problem that affects the consistency of Raman signals. Thus, microfluidic systems coupled with solid surface-based substrates, featuring stable and ordered structures, have more potential for automatic detection in practical application.

\subsection{Microfluidics with LSPR}

\subsubsection{Microfluidics Integrating LSPR Sensor for Biomolecular Detection Only}

Compared to other optical sensors, LSPR-based biosensors can be constructed in a relatively simple optical setup and minimum optical alignment. Therefore, it has been widely integrated with microfluidics for real-time, multi-parallel biomolecular monitoring in the laboratory settings or even 
in the point-of-care settings. For example, Lin et al. reported a multi-point analyte detection with a simple rapid thermal annealing (RTA)-fabricated LSPR sensor [90]. They optimized the LSPR sensor to the highest sensitivity around $189 \mathrm{~nm} \mathrm{RIU}^{-1}$ by tuning gold deposition thickness and RTA temperature. After that, a commercial microchannel was integrated with the sensor for real-time immunoglobulin $\mathrm{G}$ (IgG) detection, as shown in Figure 12A. On the other hand, multiplex analyte detection is also a popular topic for researchers. Chen et al. proposed an LSPR sensor with 480 sensing spots integrating microfluidic array. A parallel and multiplex cytokine detection (IL-2, IL-4, IL-6, IL-10, IFN- $\gamma$, and TNF- $\alpha$ ) in serum with high sensitivity of $6.46-20.56 \mathrm{pg} / \mathrm{mL}$ was demonstrated [91]. Furthermore, from the same group, Oh. et al. used this microfluidic design to detect off-chip T cell cytokine secretion profile [92], shown in Figure 12B. In essence, they used a syringe pump to load the secreted cytokine into the microfluidics. Then, the target analyte mentioned above was monitored. Yavas et al. designed dual-layer microfluidics to achieve multiplex cytokine detection [93]. Accordingly, the orthogonal microchannel was operated as a flow direction control, known as the quake valve. With the precise fluid control, sensitive LSPR sensor using amplification antibody, the researchers achieved an extremely low LOD, as shown in Figure 12C.
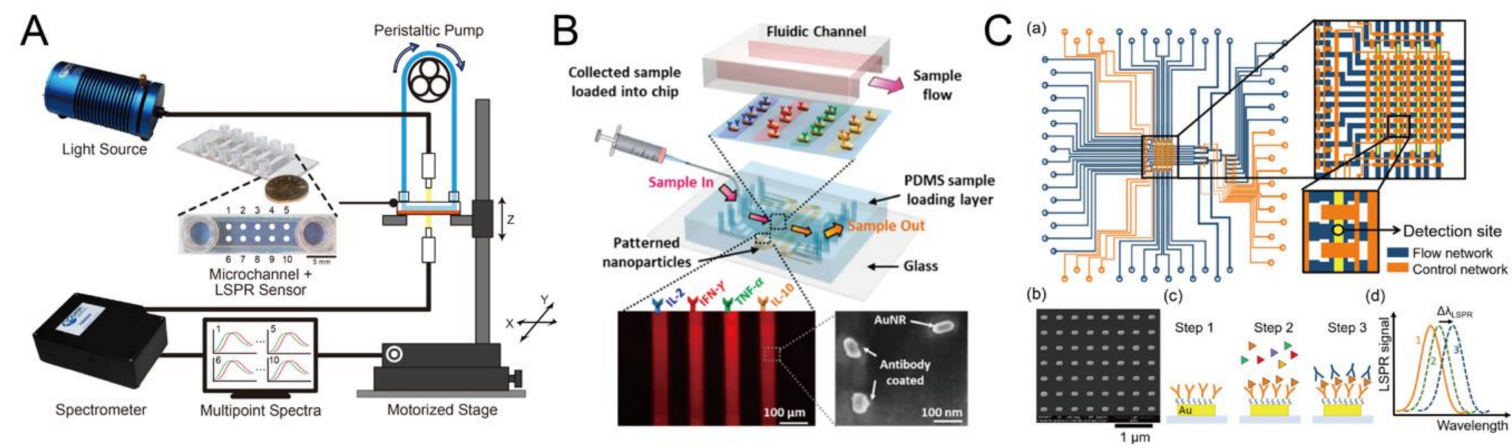

Figure 12. Biomolecular detection by optofluidic localized surface plasmon resonance (LSPR) device. (A) Schematic of the LSPR system consisting of a light source; spectrometer; peristaltic pump; LSPR sensor attached to a commercial microchannel device; and motorized stage for real-time, multi-point (10 spots) immunoglobulin G (IgG) detection. Reproduced with permission from [90]. Copyright (2017) MDPI. (B) The LSPR sensor consists of a PDMS microfluidic channel embedded with the multi-parallel AuNR (Au nanorod) array pattern coated on the glass substrate that can be used for multiplex cytokine detection. Reproduced with permission from [92]. Copyright (2016) ACS publications. (C) The quake valve-based microfluidic device integrating the gold nanorod array pattern is used for multiplex cytokine detection. Reproduced with permission from [93]. Copyright (2018) ACS publications.

3.3.2. Microfluidics Integrating LSPR Sensor for Cell Manipulation Followed by In Situ Biomolecular Detection

Besides biomolecular detection, a microfluidic device can be applied for more advanced functions, such as cell separation, cell sorting, and creating a microenvironment for cell secretion detection. Therefore, many researchers have utilized such a device for investigating cell secretory activities. For instance, $\mathrm{Wu}$ et al. [94] proposed a microfluidic channel that contains an array of U-shaped cell traps for THP-1 cells trapping followed by lipopolysaccharide (LPS) stimulation. Then, after matrix metalloproteinase 9 (MMP-9) is secreted, an LSPR-based sensor can realize the long-term, real-time, in situ monitoring. As shown in Figure 13A, Zhu et al. demonstrated multiplex cytokine (IL-6, TNF- $\alpha$, IL-10, and IL-4) detection with an LSPR sensor. Briefly, they bound a PDMS microfluidic device with a glass cover slide to construct a $4 \mathrm{~mm}$ diameter cylindrical chamber for adipocytes and macrophages culture. Then, an LSPR sensor was bound temporarily for cytokine secretion detection after lipopolysaccharide (LPS) stimulation, as shown in Figure 13B. From their results, a rapid, sensitive, multiplex, and real-time assay was achieved. Moreover, the process of adipose tissue turning into the adipocyte was also observed [95]. 

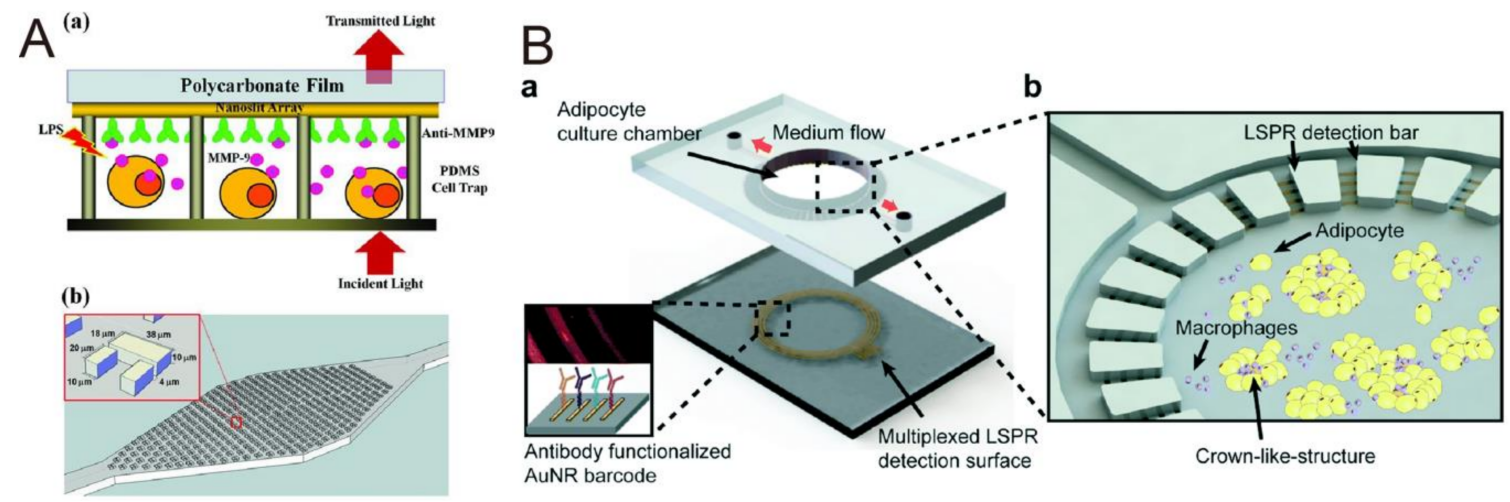

Figure 13. The microfluidic LSPR platform for on-chip cell manipulation followed by in situ biomolecular detection. (A) (a) Schematic of the device for matrix metalloproteinase 9 (MMP-9) detection. After cell stimulation, secreted-MMP-9 directly binds to the gold nanoslit array. Then, the amount of the MMP-9 secretion is measured as the transmission spectrum received. (b) The cell trapping microfluidics. Reproduced with permission from [94]. Copyright (2013) Wiley-VCH Vertag. (B) (a) Schematic of the adipocyte culture and LSPR sensing platform. The AuNR pattern coated on the glass substrate allows a multiplex cytokine measurement. The upper PDMS layer has a cylinder chamber for adipocyte culture. (b) The culture chamber surrounded by a block array provides a microenvironment for macrophage formation and can only allow the small secreted protein to pass through the gap for further LSPR sensing. Reproduced with permission from [95]. Copyright (2018) Royal Society of Chemistry.

\subsection{Microfluidics with Photonic Crystal Sensors}

PC-based sensors have been applied to biological and biochemical fields such as multiple biological target detection and biomolecular interaction analysis. Recently, analysis of membranous extracellular vesicles (EVs) such as exosome have been studied to diagnose various diseases [96]. The microfluidic PC-based biosensor only requires a small volume of sample reagents and can provide label-free, real-time analysis. Moreover, the measured time can be greatly reduced. An example is shown in Figure 14A. The surface of the PC-based biosensor was sequentially modified by polyvinylamine (PVA) and glutaraldehyde (GA). After that, CD63 antibody was also functionalized on the sensor surface to recognize CD63 presented on EVs. The changes in the refractive index caused by the recognition of EVs will be detected by PC-based biosensor. The LOD for the biosensor was $2.18 \times 10^{9} \mathrm{EVs} / \mathrm{mL}$ with high specificity. The second example is integrating a 384-well microplate with a PC-based biosensor and a series of microfluidic channel for molecular kinetic reaction rate measurement [97]. The PC structure was fabricated with a plastic-based molding process that can be inexpensively manufactured. With advantages of microfluidics such as low reagent consumption and rapid response time, this study used the heparin and lactoferrin as examples, with the device being able to measure kinetic association and dissociation rate constants by detection of analyte binding. The sensor surface was sequentially modified by amine polymer and GA. Streptavidin was added to react with GA. Finally, biotinylated heparin was immobilized as a probe for lactoferrin to measure kinetic reaction rate. The same group also demonstrated IgG protein kinetic binding response measurement in a 96-well microfluidic and microplate-based platform integrated with PC-based biosensors (Figure 14B) [98]. Protein A was immobilized on sensor surface to recognize various IgG proteins in fluid. The change of peak wavelength value (PWV) was able to be be detected by a 2D spatial image instrument to analyze the kinetic interaction. 
A

(a)

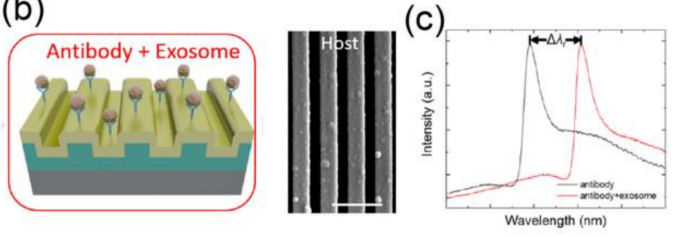

$\mathrm{B}(\mathrm{a})$

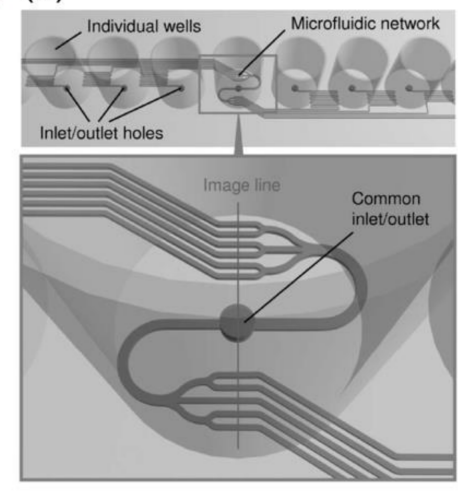

(b)

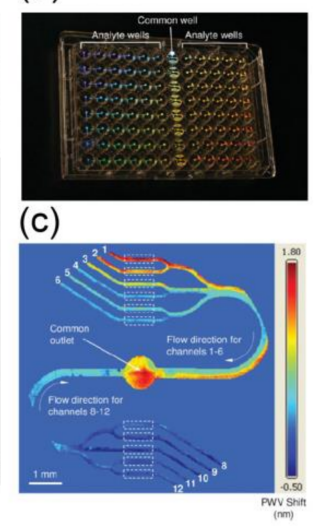

Figure 14. PC-based biosensors integrated with a microfluidic device. (A) (a) Schematic diagram of PC biosensor chips for extracellular vesicle (EV) detection. (A) (b) The mechanism for EV label-free detection and the SEM (scanning electron microscopic) image of host EVs immobilized on the PC surface. (A) (c) The binding of specific EV will affect resonant reflection and cause a spectral shift of $\Delta \lambda \mathrm{r}$. Reproduced with permission from [96]. Copyright (2018) ACS publications. (B) (a) Schematic of a 96-well microplate integrated with PC-based biosensors. (B) (b) Photograph of the bottom of the 96-well microplate incorporating microfluidic channel integrated with PC-based biosensors. (B) (c) Spatial peak wavelength value (PWV) shift image detected by 2D spatial image instrument that could be calculated by PWV shift values. Reproduced with permission from [98]. Copyright (2007) Royal Society of Chemistry.

\subsection{Microfluidics with Guided-Mode Resonator}

Currently, several research groups are already integrating the GMR sensor into the microfluidic device to produce an optofluidic system in order to shorten the reaction time for biosensing, or even to provide the functionality of the sample process. Lin et al. developed an optofluidic system capable of monitoring the dinitrophenyl/anti-dinitrophenyl interaction [99]. Their GMR sensor was composed of a cyclic olefin copolymer substrate with $416 \mathrm{~nm}$ period, $100 \mathrm{~nm}$ amplitude 1D grating, and a $125 \mathrm{~nm}$ sputtered thick $\mathrm{TiO}_{2}$ layer for waveguiding. Instead of using white light source and spectrometry, the authors utilized a low-cost LED and a photodiode as the light source and detector, respectively, in order to lower the total cost of the system (Figure 15A-a). The sensor was then bonded to a cyclic olefin copolymer (COC)-based microfluidic channel to form an optofluidic device (Figure 15A-b). More importantly, they applied the lock-in technique at $1 \mathrm{kHz}$ operation frequency to improve the SNR. From their result, the optofluidic system can achieve high refractive index $\left(4.1 \times 10^{-5} \mathrm{RIU}^{-1}\right)$ in reflection mode compared to other optical sensing techniques. Furthermore, they modified dinitrophenyl onto the $\mathrm{TiO}_{2}$ surface to perform anti-dinitrophenyl biosensing. The LOD was $75 \mathrm{ng} / \mathrm{mL}$ with 0.9858 coefficient of variance, indicating high linearity and high sensitivity of the system. To enable POC, the direct cellular or biomolecular analysis of a real clinical sample will be a huge obstacle due to its complexity and variation between different patients. Hence, the microfluidic-based sample process becomes a critical module for system integration. Taking blood as an example, the existence of blood cells and debris will affect optical sensing by generating extra absorption and scattered light. In order to eliminate the interference, the plasma should be extracted first by removing all the cells and debris. On the basis of this concept, Tsai et al. proposed a microfluidic with a blood process module integrating GMR sensor for diluted blood sample analysis [100]. The microfluidic device can be divided into two regions-filter region and sensing region. In the filter region, a micropost array was fabricated to extract the plasma from 10,000x diluted blood by filtering the cells. In sensing region, a GMR sensor, composed of PMMA substrate, an optical adhesive grating with $555.5 \mathrm{~nm}$ period/110 nm depth, and a $\mathrm{TiO}_{2}$ layer, was integrated by a double-sided tape. The device was reported to have $186 \mathrm{~nm} / \mathrm{RIU}$ sensitivity from the sucrose solution. The device then performed biosensing of $\mathrm{C}$-reactive protein 
and the corresponding limit of detection was $3.2 \mathrm{ng} / \mathrm{mL}$ with approximately five orders of dynamic range. Compared to ELISA (enzyme-linked immunosorbent assay) kit, their device had higher LOD but wider dynamic range. Most importantly, they introduced rat blood to the microfluidic device for C-reactive protein (CRP) on-chip sensing and compared the results of direct sensing from plasma or blood. In terms of the peak shift, the shift of on-chip sensing was identical to that of direct sensing from plasma. However, the shift of direct sensing from whole blood was shown to have higher peak shift due to the interference of blood cells and debris.

A

(a)

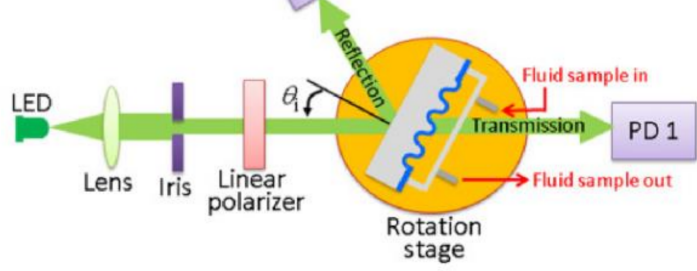

(b)

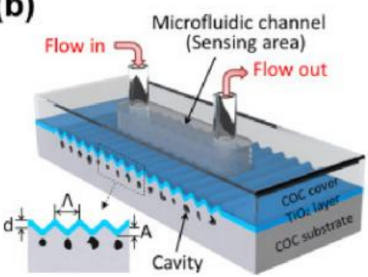

(c)

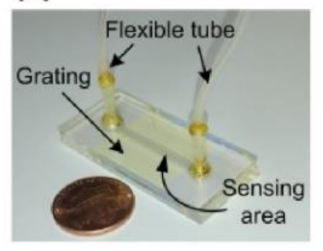

B

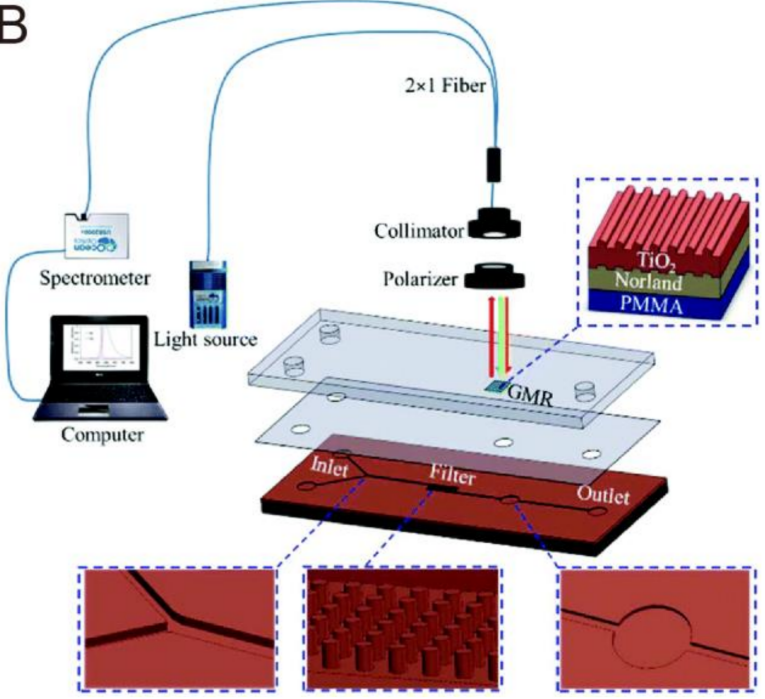

Figure 15. (A) (a) Schematic of the GMR optofluidic sensing system. (b) Schematic and (c) optical image of the disposable GMR biosensor chip. Reproduced with permission from [99]. Copyright (2017) Elsevier. (B) Schematic of the three-layer lab-on-chip system and optical read-out setup. Reproduced with permission from [100]. Copyright (2018) Royal Society of Chemistry.

\section{Application of Integrated Sensors to Point-of-Care}

\subsection{Review of Integrated Biosensors and Future Trend}

The aforementioned optical biosensors integrated with various technologies have the potential to provide more accurate and more comprehensive diagnoses of diseases. For further POCT applications, it is necessary that the integrated optical sensors are low-cost, have rapid detection, and are simple to operate when migrating from laboratory tests to near the patient diagnosis.

There are new or evolving technologies that have the potential to disrupt the established POC diagnosis. In our opinion, recent optical biosensor development for POCT can be categorized in the following ways:

- Lab-on-a-chip: Microfluidic techniques have been extensively employed for POC biosensors. The integration of microfluidic and optical techniques as elaborated in the previous sections incorporates several sensing functions in a chip, in addition to target analyte delivery, thus simplifying the steps of testing and enabling the miniaturization of biomedical devices [101].

- Surface tension or evaporation-induced flow: Since the sample volume can be greatly reduced in the microfluidic devices, the flow driven force can be generated by surface tension or evaporation driven flow, which can eliminate the requirement of external pump or further enrich targeted molecules to achieve a higher sensitivity. For example, Kumar et al. demonstrated a surface tension-driven flow to guide 4-mercaptopyridine into a suspended plasmonic nanohole array for SERS detection [102]. Regarding to the molecule concentration, one example involves the evaporation-induced spontaneous flow of $100 \mathrm{pL}$ inkjet-printed droplets on the photonic crystal 
biosilia to perform SERS detection [103]. Another method is using the pyro-dispensing technique to guide and concentrate targeted molecules into the fluorescence-based sensing substrate. [104].

- Lateral flow and vertical flow immunoassays: Lateral flow immunoassay (LFI) is one of the most mature POC technologies [105]. Examples of lateral flow tests include pregnancy, infectious diseases, cancer, cardiac diseases, illicit drug abuse, and influenza tests [106,107]. The alternative to LFIA is vertical flow immunoassay (VFI), which offers several key advantages, including faster analysis time and the absence of a false-negative inducing hook effect [108]. The VFI has been explored to detect antibody in human serum and bio-threat pathogens, among others $[109,110]$.

- Wearable and continuous monitoring: Continuous monitoring of chronic disease and wellness is one of the most significant advances of POCT. For example, the Apple watch, a wearable device, uses green LED lights paired with light-sensitive photodiodes to detect the amount of blood flowing through the wrist at any given moment. The heart rate and electrocardiogram (ECG) are monitored [111]. Another example is for diabetes, wherein many commercial devices focus on continuous glucose monitoring (CGM) in various body fluids [112].

- DNA sequencing: DNA sequencing has become indispensable for basic biological research, biotechnology, and medical diagnosis. In recent years, DNA sequencing has been employed in the medical facility to determine if there is risk of genetic diseases in patients. Health analysts have predicted that DNA sequencing will shift from a laboratory-based analysis to POC performed by the patients off-site within the next five years [113].

A brief summary of integrated optical biosensors in recent years for POC applications is listed in Table 1. They are mainly, but not all, based on the microfluidic platform. We believe in the near future there will be more optical biosensors integrated with technologies beyond microfluidic channels for POCT.

Table 1. Review of optical biosensors with various sensing technologies for point-of-care (POC).

\begin{tabular}{|c|c|c|c|}
\hline Sensor Type & Detector Technology & Target Analyte & Reference \\
\hline \multirow{2}{*}{ Fluorescent } & Microfluidic and FRET & Noroviruses (NoV) & [16] \\
\hline & $\begin{array}{l}\text { Microfluidic and loop-mediated } \\
\text { isothermal amplification (LAMP) }\end{array}$ & Neisseria meningitidis & [114] \\
\hline \multirow[t]{2}{*}{ Colorimetric } & $\begin{array}{l}\text { ELISA and cell phone/charge-coupled } \\
\text { device (CCD) }\end{array}$ & Ovarian cancer HE4 biomarker & [17] \\
\hline & $\begin{array}{l}\text { USB interface mobile platform, } \\
\text { microfluidic and ELISA }\end{array}$ & BDE-47 & [115] \\
\hline \multirow{4}{*}{ SPR } & Microfluidic and SPR & $\begin{array}{c}\text { Escherichia coli } \\
\text { Staphylococcus aureus }\end{array}$ & [18] \\
\hline & $\begin{array}{l}\text { SAW (surface acoustic wave), } \\
\text { microfluidic and SPR }\end{array}$ & Avidin-biotin binding & [116] \\
\hline & SAW and SPR & AFB1 & [117] \\
\hline & LSPR and microfluidic & Protein binding & [118] \\
\hline GMR & $\begin{array}{l}\text { GMR, microfluidic and a CMOS } \\
\text { (complementary metal oxide } \\
\text { semiconductor) camera }\end{array}$ & $\operatorname{IgG}$ & [19] \\
\hline PC & PC and microfluidic & $\begin{array}{l}\text { CD40 ligand antibody } \\
\text { EGF antibody } \\
\text { Streptavidin } \\
\text { Thrombin }\end{array}$ & [119] \\
\hline \multirow{2}{*}{ SERS } & SERS and microfluidic & Hepatitis B virus antigen & [20] \\
\hline & SERS and microfluidic & Rabbit IgG protein & [120] \\
\hline
\end{tabular}




\subsection{Market and Future Perspectives}

Depending on the definition of the POC market, the estimation of the overall market size of POC varies but was generally reckoned to be more than USD 20 billion in 2018, with a CAGR (compound annual growth rate) within the next 5 years of around 10\% [121-123]. The pregnancy test and CGM led the POCT market in recent years but their growth has been saturated. The awareness of healthcare and disease prevalence in developed countries are the driving forces for the growth of the POCT market [124]. In developing countries such as China and India, the demand of POCT is growing at a faster pace as more of the population enters the middle class and increases the demand for a high standard of healthcare [124]. For rural areas where medical resources are limited, POCT plays a critical role in timely availability of medical diagnosis. To satisfy the demand on detecting multiple diseases with high accuracy, we anticipate that integrated biosensors will be the future trend of POCT.

\section{Conclusions}

In this article, we overviewed optical biosensing technologies. Some, such as SPR, fluorescence, and Bragg grating are commercially available, while others are currently only found in laboratory testing. The rapid growth of POCT changes the landscape of biosensor development and future business opportunities. We envision that there are more integrated optical biosensors for POC. The integrated optical biosensors have many advantages. First, the integration miniaturizes the components that construct optical biosensors. Second, the sensitivities and accuracy can be further improved by incorporating other physical, mechanical, and electrical sensing technologies. Many optical biosensors facilitate microfluidic for target analyte delivery, miniaturization, and performance improvement. On the other hand, the integration of optical biosensors with field-effect electrical charge sensing is rare. We expect there will be more optical biosensors that simultaneously extract the electrical charge properties of the target analyte on the basis of semiconductor fabrication. The integrated optical biosensors are for the benefit of POC. Future perspectives in the development of biosensors, in our opinion, are on the continuous improvement of lab-on-a-chip, LFI and VFI, wearable and continuous-monitoring, and DNA sequencing. Optical biosensors will play an indispensable role in future POCT by integrating with microfluidic, mechanical, and electrical biosensing technologies.

Author Contributions: Conceptualization, N.-T.H., C.-T.L. and J.-J.H.; literature survey and data collection; Y.-T.C., Y.-C.L., Y.-H.L. and J.-C.L.; literature analysis: N.-T.H. and J.-J.H.; writing-original draft preparation, N.-T.H., C.-T.L. and J.-J.H.; writing-review and editing, N.-T.H., and J.-J.H.; supervision and project administration, J.-J.H. All authors have read and agreed to the published version of the manuscript.

Funding: This work was supported by Ministry of Science and Technology of Taiwan under the grants MOST 108-2221-E-002-014-MY3.

Conflicts of Interest: The authors declare no conflict of interest.

\section{References}

1. Sethi, R.S. Transducer aspects of biosensors. Biosens. Bioelectron. 1994, 9, 243-264. [CrossRef]

2. DeLouise, L.A.; Kou, P.M.; Miller, B.L. Cross-Correlation of Optical Microcavity Biosensor Response with Immobilized Enzyme Activity. Insights into Biosensor Sensitivity. Anal. Chem. 2005, 77, 3222-3230. [CrossRef] [PubMed]

3. Song, S.; Wang, L.; Li, J.; Fan, C.; Zhao, J. Aptamer-based biosensors. TrAC Trends Anal. Chem. 2008, 27, 108-117. [CrossRef]

4. Lin, V.S.-Y.; Motesharei, K.; Dancil, K.-P.S.; Sailor, M.J.; Ghadiri, M.R. A Porous Silicon-Based Optical Interferometric Biosensor. Science 1997, 278, 840-843. [CrossRef]

5. Roger, J.N. Woodhead Publishing Series in Biomaterials. In Medical Biosensors for Point of Care (POC) Applications; Narayan, R.J., Ed.; Woodhead Publishing: Sawston, Cambridge, UK, 2017; pp. 3-25.

6. Ahmed, M.U.; Saaem, I.; Wu, P.C.; Brown, A.S. Personalized diagnostics and biosensors: A review of the biology and technology needed for personalized medicine. Crit. Rev. Biotechnol. 2014, 34, 180-196. [CrossRef] 
7. Wangping, D.; Lihua, W.; Shiping, S.; Xiaolei, Z. Biosensors in POCT Application. Prog. Chem. 2016, 28, 1341-1350. [CrossRef]

8. Dhawan, A.P.; Heetderks, W.J.; Pavel, M.; Acharya, S.; Akay, M.; Mairal, A.; Wheeler, B.; Dacso, C.C.; Sunder, T.; Lovell, N.H.; et al. Current and Future Challenges in Point-of-Care Technologies: A Paradigm-Shift in Affordable Global Healthcare with Personalized and Preventive Medicine. IEEE J. Transl. Eng. Health Med. 2015, 3, 1-10. [CrossRef]

9. Yang, J. Blood glucose monitoring with smartphone as glucometer. Electrophoresis 2019, 40, 1144-1147. [CrossRef]

10. Li, C.-Z. Special Topic: Point-of-Care Testing (POCT) and In Vitro Diagnostics (IVDs). J. Anal. Test. 2019, 3, 1-2. [CrossRef]

11. Sri, S.; Dhand, C.; Rathee, J.; Ramakrishna, S.; Solanki, P.R. Microfluidic Based Biosensors as Point of Care Devices for Infectious Diseases Management. Sens. Lett. 2018, 17, 4-16. [CrossRef]

12. Shafiee, H.; Wang, S.; Inci, F.; Toy, M.; Henrich, T.J.; Kuritzkes, D.R.; Demirci, U. Emerging Technologies for Point-of-Care Management of HIV Infection. Annu. Rev. Med. 2015, 66, 387-405. [CrossRef] [PubMed]

13. Li, F.; Li, H.; Wang, Z.; Wu, J.; Wang, W.; Zhou, L.; Xiao, Q.; Pu, Q. Mobile phone mediated point-of-care testing of HIV p24 antigen through plastic micro-pit array chips. Sens. Actuators B Chem. 2018, 271, 189-194. [CrossRef]

14. Luka, G.; Ahmadi, A.; Najjaran, H.; Alocilja, E.C.; DeRosa, M.C.; Wolthers, K.R.; Malki, A.; Aziz, H.; Al Thani, A.A.; Hoorfar, M. Microfluidics Integrated Biosensors: A Leading Technology towards Lab-on-a-Chip and Sensing Applications. Sensors 2015, 15, 30011-30031. [CrossRef] [PubMed]

15. Dincer, C.; Bruch, R.; Kling, A.; Dittrich, P.S.; Urban, G.A. Multiplexed Point-of-Care Testing-xPOCT. Trends Biotechnol. 2017, 35, 728-742. [CrossRef] [PubMed]

16. Weng, X.; Neethirajan, S. Rapid Detection of Norovirus Using Paper-based Microfluidic Device. bioRxiv 2017, 162396.

17. Wang, S.; Zhao, X.; Khimji, I.; Akbas, R.; Qiu, W.; Edwards, D.; Cramer, D.W.; Ye, B.; Demirci, U. Integration of cell phone imaging with microchip ELISA to detect ovarian cancer HE4 biomarker in urine at the point-of-care. Lab Chip 2011, 11, 3411-3418. [CrossRef] [PubMed]

18. Tokel, O.; Yildiz, U.H.; Inci, F.; Durmus, N.G.; Ekiz, O.O.; Turker, B.; Cetin, C.; Rao, S.; Sridhar, K.; Natarajan, N.; et al. Portable Microfluidic Integrated Plasmonic Platform for Pathogen Detection. Sci. Rep. 2015, 5, 9152. [CrossRef]

19. Triggs, G.J.; Wang, Y.; Reardon, C.P.; Fischer, M.; Evans, G.J.O.; Krauss, T.F. Chirped guided-mode resonance biosensor. Optica 2017, 4, 229-234. [CrossRef]

20. Kamińska, A.; Witkowska, E.; Winkler, K.; Dzięcielewski, I.; Weyher, J.L.; Waluk, J. Detection of Hepatitis B virus antigen from human blood: SERS immunoassay in a microfluidic system. Biosens. Bioelectron. 2015, 66, 461-467. [CrossRef]

21. Sarangadharan, I.; Regmi, A.; Chen, Y.-W.; Hsu, C.-P.; Chen, P.-C.; Chang, W.-H.; Lee, G.-Y.; Chyi, J.-I.; Shiesh, S.-C.; Lee, G.-B.; et al. High sensitivity cardiac troponin I detection in physiological environment using AlGaN/GaN High Electron Mobility Transistor (HEMT) Biosensors. Biosens. Bioelectron. 2018, 100, 282-289. [CrossRef]

22. Wang, Y.; Luo, J.; Liu, J.; Li, X.; Kong, Z.; Jin, H.; Cai, X. Electrochemical integrated paper-based immunosensor modified with multi-walled carbon nanotubes nanocomposites for point-of-care testing of $17 \beta$-estradiol. Biosens. Bioelectron. 2018, 107, 47-53. [CrossRef] [PubMed]

23. Bounik, R.; Gusmaroli, M.; Misun, P.M.; Viswam, V.; Hierlemann, A.; Modena, M.M. Integration of Discrete Sensors and Microelectrode Arrays into Open Microfluidic Hanging-Drop Networks. In Proceedings of the 2019 IEEE 32nd International Conference on Micro Electro Mechanical Systems (MEMS), Seoul, Korea, 27-31 January 2019; pp. 441-444.

24. Zaki, A.; Kirah, K.; Swillam, M.A. Integrated optical sensor using hybrid plasmonics for lab on chip applications. J. Opt. 2016, 18, 085803. [CrossRef]

25. Arjang, H.; Arun, M.; Rituraj, S. Integrated Optical Biosensor Array Including Charge Injection Circuit and Quantizer Circuit. United States Patent US8969781, 3 March 2015. Available online: https://repositories.lib. utexas.edu/handle/2152/76653 (accessed on 12 December 2020). [CrossRef]

26. Caucheteur, C.; Guo, T.; Albert, J. Review of plasmonic fiber optic biochemical sensors: Improving the limit of detection. Anal. Bioanal. Chem. 2015, 407, 3883-3897. [CrossRef] [PubMed] 
27. Benito-Peña, E.; Valdés, M.G.; Glahn-Martínez, B.; Moreno-Bondi, M.C. Fluorescence based fiber optic and planar waveguide biosensors. A review. Anal. Chim. Acta 2016, 943, 17-40. [CrossRef] [PubMed]

28. Hong, L.; McManus, S.; Yang, H.; Sengupta, K. In A fully integrated CMOS fluorescence biosensor with on-chip nanophotonic filter. In Proceedings of the 2015 Symposium on VLSI Circuits (VLSI Circuits), Kyoto, Japan, 15-19 June 2015; p. 206.

29. Strianese, M.; Staiano, M.; Ruggiero, G.; Labella, T.; Pellecchia, C.; D'Auria, S. Fluorescence-based biosensors. Methods Mol. Biol. Clifton N. J. 2012, 875, 193-216.

30. Tainaka, K.; Sakaguchi, R.; Hayashi, H.; Nakano, S.; Liew, F.F.; Morii, T. Design Strategies of Fluorescent Biosensors Based on Biological Macromolecular Receptors. Sensors 2010, 10, 1355-1376. [CrossRef]

31. Jensen, E.C. Use of Fluorescent Probes: Their Effect on Cell Biology and Limitations. Anat. Rec. Adv. Integr. Anat. Evol. Biol. 2012, 295, 2031-2036. [CrossRef]

32. Nawrot, W.; Drzozga, K.; Baluta, S.; Cabaj, J.; Malecha, K. A Fluorescent Biosensors for Detection Vital Body Fluids' Agents. Sensors 2018, 18, 2357. [CrossRef]

33. Pilot, R.; Signorini, R.; Durante, C.; Orian, L.; Bhamidipati, M.; Fabris, L. A Review on Surface-Enhanced Raman Scattering. Biosensors 2019, 9, 57. [CrossRef]

34. Campion, A.; Kambhampati, P. Surface-enhanced Raman scattering. Chem. Soc. Rev. 1998, 27, $241-250$. [CrossRef]

35. Schatz, G.C.; Young, M.A.; Van Duyne, R.P. Electromagnetic Mechanism of SERS. In Surface-Enhanced Raman Scattering: Physics and Applications; Kneipp, K., Moskovits, M., Kneipp, H., Eds.; Springer: Berlin/Heidelberg, Germany, 2006; pp. 19-45.

36. Birke, R.L.; Lombardi, J.R. Surface-Enhanced Raman Scattering. In Spectroelectrochemistry: Theory and Practice; Gale, R.J., Ed.; Springer: Boston, MA, USA, 1988; pp. 263-348.

37. Lombardi, J.R.; Birke, R.L. A Unified View of Surface-Enhanced Raman Scattering. Accounts Chem. Res. 2009, 42, 734-742. [CrossRef] [PubMed]

38. McCreery, R.L. Raman Spectroscopy for Chemical Analysis; John Wiley \& Sons: Hoboken, NJ, USA, 2000.

39. Jeon, T.Y.; Kim, D.-H.; Park, S.-G.; Kim, S.-H. Nanostructured plasmonic substrates for use as SERS sensors. Nano Converg. 2016, 3, 1-20. [CrossRef] [PubMed]

40. Bantz, K.C.; Meyer, A.F.; Wittenberg, N.J.; Im, H.; Kurtuluş, Ö.; Lee, S.H.; Lindquist, N.C.; Oh, S.-H.; Haynes, C.L. Recent progress in SERS biosensing. Phys. Chem. Chem. Phys. 2011, 13, 11551-11567. [CrossRef] [PubMed]

41. Kim, J.; Jang, Y.; Kim, N.-J.; Kim, H.; Yi, G.-C.; Shin, Y.; Kim, M.H.; Yoon, S. Study of Chemical Enhancement Mechanism in Non-plasmonic Surface Enhanced Raman Spectroscopy (SERS). Front. Chem. 2019, 7, 582. [CrossRef]

42. Ringe, E.; Sharma, B.; Henry, A.-I.; Marks, L.D.; Van Duyne, R.P. Single nanoparticle plasmonics. Phys. Chem. Chem. Phys. 2013, 15, 4110-4129. [CrossRef]

43. Lenzi, E.; De Aberasturi, D.J.; Liz-Marzán, L.M. Surface-Enhanced Raman Scattering Tags for Three-Dimensional Bioimaging and Biomarker Detection. ACS Sens. 2019, 4, 1126-1137. [CrossRef]

44. Yu, Y.; Xie, Y.; Zeng, P.; Zhang, D.; Liang, R.; Wang, W.; Ou, Q.; Zhang, S. Morphology-Tailored Gold Nanoraspberries Based on Seed-Mediated Space-Confined Self-Assembly. Nanomaterials 2019, 9, 1202. [CrossRef]

45. Li, J.-H.; Chen, S.-W.; Chou, Y.; Wu, M.-C.; Hsueh, C.-H.; Su, W.-F. Effects of Gold Film Morphology on Surface Plasmon Resonance Using Periodic P3HT:PMMA/Au Nanostructures on Silicon Substrate for Surface-Enhanced Raman Scattering. J. Phys. Chem. C 2011, 115, 24045-24053. [CrossRef]

46. Cunningham, B.T.; Li, P.; Schulz, S.C.; Lin, B.; Baird, C.L.; Gerstenmaier, J.; Genick, C.; Wang, F.; Fine, E.; Laing, L.G. Label-Free Assays on the BIND System. J. Biomol. Screen. 2004, 9, 481-490. [CrossRef]

47. Fang, Y.; Ferrie, A.M.; Fontaine, N.H.; Mauro, J.C.; Balakrishnan, J. Resonant Waveguide Grating Biosensor for Living Cell Sensing. Biophys. J. 2006, 91, 1925-1940. [CrossRef]

48. Cunningham, B.T.; Zhang, M.; Zhuo, Y.; Kwon, L.; Race, C. Recent Advances in Biosensing with Photonic Crystal Surfaces: A Review. IEEE Sens. J. 2016, 16, 3349-3366. [CrossRef] [PubMed]

49. Konopsky, V.N.; Alieva, E.V. Optical Biosensors Based on Photonic Crystal Surface Waves. Methods Mol. Biol. Clifton N. J. 2009, 503, 49-64. 
50. Zhang, M.; Peh, J.; Hergenrother, P.J.; Cunningham, B.T. Detection of Protein-Small Molecule Binding Using a Self-Referencing External Cavity Laser Biosensor. J. Am. Chem. Soc. 2014, 136, 5840-5843. [CrossRef] [PubMed]

51. Shafiee, H.; Lidstone, E.A.; Jahangir, M.; Inci, F.; Hanhauser, E.; Henrich, T.J.; Kuritzkes, D.R.; Cunningham, B.T.; Demirci, U. Nanostructured Optical Photonic Crystal Biosensor for HIV Viral Load Measurement. Sci. Rep. 2014, 4, 4116. [CrossRef]

52. George, S.; Block, I.D.; Jones, S.I.; Mathias, P.C.; Chaudhery, V.; Vuttipittayamongkol, P.; Wu, H.-Y.; Vodkin, L.O.; Cunningham, B.T. Label-Free Prehybridization DNA Microarray Imaging Using Photonic Crystals for Quantitative Spot Quality Analysis. Anal. Chem. 2010, 82, 8551-8557. [CrossRef]

53. Kwon, L.; Race, C.; Foreman, M.; Cunningham, B. An automated microfluidic assay for the detection of cancer biomarkers in serum using photonic crystal enhanced fluorescence. In Proceedings of the 2016 IEEE Sensors, Orlando, FL, USA, 30 October-3 November 2016; pp. 1-3. [CrossRef]

54. Petrova, I.; Konopsky, V.; Nabiev, I.; Sukhanova, A. Label-Free Flow Multiplex Biosensing via Photonic Crystal Surface Mode Detection. Sci. Rep. 2019, 9, 1-9. [CrossRef]

55. Quaranta, G.; Basset, G.; Martin, O.J.F.; Gallinet, B. Recent Advances in Resonant Waveguide Gratings. Laser Photon Rev. 2018, 12, 1800017. [CrossRef]

56. Sun, T.; Wu, D. Guided-mode resonance excitation on multimode planar periodic waveguide. J. Appl. Phys. 2010, 108, 063106. [CrossRef]

57. Rosenblatt, D.; Sharon, A.; Friesem, A.A. Resonant grating waveguide structures. IEEE J. Quantum Electron. 1997, 33, 2038-2059. [CrossRef]

58. Sahoo, P.K.; Sarkar, S.; Joseph, J. High sensitivity guided-mode-resonance optical sensor employing phase detection. Sci. Rep. 2017, 7, 1-7. [CrossRef]

59. Robert, M.; Kyu, J.L.; Hafez, H.; Yeong Hwan, K.; Brett, R.W.; Jeffery, W.A.; Monica, S.A.; Susanne, G.; Debra Wawro, W. The guided-mode resonance biosensor: Principles, technology, and implementation. Proc. SPIE 2018, 10510. [CrossRef]

60. Moghaddas, S.A.J.; Shahabadi, M.; Mohammad-Taheri, M. Guided Mode Resonance Sensor with Enhanced Surface Sensitivity Using Coupled Cross-Stacked Gratings. IEEE Sensors J. 2014, 14, 1216-1222. [CrossRef]

61. Zhou, Y.; Wang, B.; Guo, Z.; Wu, X. Guided Mode Resonance Sensors with Optimized Figure of Merit. Nanomaterials 2019, 9, 837. [CrossRef] [PubMed]

62. Sahoo, P.R.; Swain, P.; Nayak, S.M.; Bag, S.; Mishra, S.R. Surface plasmon resonance based biosensor: A new platform for rapid diagnosis of livestock diseases. Veter World 2016, 9, 1338-1342. [CrossRef] [PubMed]

63. Tang, Y.; Zeng, X.; Liang, J. Surface Plasmon Resonance: An Introduction to a Surface Spectroscopy Technique. J. Chem. Educ. 2010, 87, 742-746. [CrossRef]

64. Zhao, Y.; Gan, S.; Zhang, G.; Dai, X. High sensitivity refractive index sensor based on surface plasmon resonance with topological insulator. Results Phys. 2019, 14, 102477. [CrossRef]

65. Šípová, H.; Homola, J. Surface plasmon resonance sensing of nucleic acids: A review. Anal. Chim. Acta 2013, 773, 9-23. [CrossRef]

66. Homola, J. Surface Plasmon Resonance Sensors for Detection of Chemical and Biological Species. Chem. Rev. 2008, 108, 462-493. [CrossRef]

67. Prabowo, B.A.; Purwidyantri, A.; Liu, K.C. Surface Plasmon Resonance Optical Sensor: A Review on Light Source Technology. Biosensors 2018, 8, 80. [CrossRef]

68. Chowdhury, A.D.; Nasrin, F.; Gangopadhyay, R.; Ganganboina, A.B.; Takemura, K.; Kozaki, I.; Honda, H.; Harae, T.; Abe, F.; Park, S.; et al. Controlling distance, size and concentration of nanoconjugates for optimized LSPR based biosensors. Biosens. Bioelectron. 2020, 170, 112657. [CrossRef]

69. Gorodkiewicz, E.; Lukaszewski, Z. Recent Progress in Surface Plasmon Resonance Biosensors (2016 to Mid-2018). Biosensors 2018, 8, 132. [CrossRef] [PubMed]

70. Ma, L.; Yang, F.; Zheng, J. Application of fluorescence resonance energy transfer in protein studies. J. Mol. Struct. 2014, 1077, 87-100. [CrossRef] [PubMed]

71. Didenko, V.V. DNA Probes Using Fluorescence Resonance Energy Transfer (FRET): Designs and Applications. Biotechniques 2001, 31, 1106-1121. [CrossRef] [PubMed]

72. Srisa-Art, M.; Sharma, S. Droplet-Based Microfluidics for Binding Assays and Kinetics Based on FRET. Methods Mol. Biol. Clifton N. J. 2013, 949, 231-240. 
73. Robinson, T.; Valluri, P.; Manning, H.B.; Owen, D.M.; Munro, I.; Talbot, C.B.; Dunsby, C.; Eccleston, J.F.; Baldwin, G.S.; Neil, M.; et al. Three-dimensional molecular mapping in a microfluidic mixing device using fluorescence lifetime imaging. Opt. Lett. 2008, 33, 1887. [CrossRef]

74. Herman, P.; Holoubek, A.; Brodska, B. Lifetime-based photoconversion of EGFP as a tool for FLIM. Biochim. Biophys. Acta BBA Gen. Subj. 2019, 1863, 266-277. [CrossRef]

75. Dittrich, P.S.; Schwille, P. An Integrated Microfluidic System for Reaction, High-Sensitivity Detection, and Sorting of Fluorescent Cells and Particles. Anal. Chem. 2003, 75, 5767-5774. [CrossRef]

76. Huang, N.-T.; Truxal, S.C.; Tung, Y.-C.; Hsiao, A.Y.; Luker, G.D.; Takayama, S.; Kurabayashi, K. Multiplexed Spectral Signature Detection for Microfluidic Color-Coded Bioparticle Flow. Anal. Chem. 2010, 82, 9506-9512. [CrossRef]

77. Baret, J.-C.; Miller, O.J.; Taly, V.; Ryckelynck, M.; El-Harrak, A.; Frenz, L.; Rick, C.; Samuels, M.L.; Hutchison, J.B.; Agresti, J.J.; et al. Fluorescence-activated droplet sorting (FADS): Efficient microfluidic cell sorting based on enzymatic activity. Lab Chip 2009, 9, 1850-1858. [CrossRef]

78. Yokokawa, R.; Kitazawa, Y.; Terao, K.; Okonogi, A.; Kanno, I.; Kotera, H. A perfusable microfluidic device with on-chip total internal reflection fluorescence microscopy (TIRFM) for in situ and real-time monitoring of live cells. Biomed. Microdevices 2012, 14, 791-797. [CrossRef]

79. Huang, N.-T.; Hwong, Y.-J.; Lai, R.L. A microfluidic microwell device for immunomagnetic single-cell trapping. Microfluid. Nanofluidics 2018, 22, 16. [CrossRef]

80. Kumar, S.; Park, H.; Cho, H.; Siddique, R.H.; Narasimhan, V.; Yang, D.; Choo, H. Overcoming evanescent field decay using 3D-tapered nanocavities for on-chip targeted molecular analysis. Nat. Commun. 2020, 11, 1-9. [CrossRef] [PubMed]

81. Tung, Y.-C.; Huang, N.-T.; Oh, B.-R.; Patra, B.; Pan, C.-C.; Qiu, T.; Chu, P.K.; Zhang, W.; Kurabayashi, K. Optofluidic detection for cellular phenotyping. Lab Chip 2012, 12, 3552-3565. [CrossRef] [PubMed]

82. Pu, H.; Xiao, W.; Sunabcd, D.-W. SERS-microfluidic systems: A potential platform for rapid analysis of food contaminants. Trends Food Sci. Technol. 2017, 70, 114-126. [CrossRef]

83. Kant, K.; Abalde-Cela, S. Surface-Enhanced Raman Scattering Spectroscopy and Microfluidics: Towards Ultrasensitive Label-Free Sensing. Biosensors 2018, 8, 62. [CrossRef]

84. Mao, H.; Wu, W.; She, D.; Sun, G.; Lv, P.; Xu, J. Microfluidic Surface-Enhanced Raman Scattering Sensors Based on Nanopillar Forests Realized by an Oxygen-Plasma-Stripping-of-Photoresist Technique. Small 2014, 10, 127-134. [CrossRef]

85. Wang, Y.-Y.; Cheng, H.-W.; Chang, K.-W.; Shiue, J.; Wang, J.-K.; Wang, Y.-L.; Huang, N.-T. A particle-based microfluidic molecular separation integrating surface-enhanced Raman scattering sensing for purine derivatives analysis. Microfluid. Nanofluidics 2019, 23, 48. [CrossRef]

86. Hidi, I.J.; Jahn, M.; Weber, K.; Bocklitz, T.; Pletz, M.W.; Cialla-May, D.; Popp, J. Lab-on-a-Chip-Surface Enhanced Raman Scattering Combined with the Standard Addition Method: Toward the Quantification of Nitroxoline in Spiked Human Urine Samples. Anal. Chem. 2016, 88, 9173-9180. [CrossRef]

87. Jahn, I.J.; Žukovskaja, O.; Zheng, X.-S.; Weber, K.; Bocklitz, T.; Cialla-May, D.; Popp, J. Surface-enhanced Raman spectroscopy and microfluidic platforms: Challenges, solutions and potential applications. Analyst 2017, 142, 1022-1047. [CrossRef]

88. Wu, L.; Wang, Z.; Cui, Y. A SERS-Assisted 3D Barcode Chip for Multiplex Protein Analysis, Optics in the Life Sciences, Vancouver, 2015/04/12; Optical Society of America: Vancouver, BC, Canada, 2015; p. BW2A.6.

89. Zheng, Z.; Wu, L.; Li, L.; Zong, S.; Wang, Z.; Cui, Y. Simultaneous and highly sensitive detection of multiple breast cancer biomarkers in real samples using a SERS microfluidic chip. Talanta 2018, 188, 507-515. [CrossRef]

90. Lin, H.T.-H.; Yang, C.-K.; Lin, C.-C.; Wu, A.M.-H.; Wang, L.A.; Huang, N.-T. A Large-Area Nanoplasmonic Sensor Fabricated by Rapid Thermal Annealing Treatment for Label-Free and Multi-Point Immunoglobulin Sensing. Nanomaterials 2017, 7, 100. [CrossRef] [PubMed]

91. Chen, P.; Chung, M.T.; McHugh, W.; Nidetz, R.; Li, Y.; Fu, J.; Cornell, T.T.; Shanley, T.P.; Kurabayashi, K. Multiplex Serum Cytokine Immunoassay Using Nanoplasmonic Biosensor Microarrays. ACS Nano 2015, 9, 4173-4181. [CrossRef] [PubMed]

92. Oh, B.-R.; Chen, P.; Nidetz, R.; McHugh, W.M.; Fu, J.; Shanley, T.P.; Cornell, T.T.; Kurabayashi, K. Multiplexed Nanoplasmonic Temporal Profiling of T-Cell Response under Immunomodulatory Agent Exposure. ACS Sens. 2016, 1, 941-948. [CrossRef] [PubMed] 
93. Yavas, O.; Aćimović, S.S.; Garcia-Guirado, J.; Berthelot, J.; Dobosz, P.; Sanz, V.; Quidant, R. Self-Calibrating On-Chip Localized Surface Plasmon Resonance Sensing for Quantitative and Multiplexed Detection of Cancer Markers in Human Serum. ACS Sens. 2018, 3, 1376-1384. [CrossRef] [PubMed]

94. Wu, S.-H.; Lee, K.-L.; Chiou, A.; Cheng, X.; Wei, P.-K. Optofluidic Platform for Real-Time Monitoring of Live Cell Secretory Activities Using Fano Resonance in Gold Nanoslits. Small 2013, 9, 3532-3540. [CrossRef] [PubMed]

95. Zhu, J.; He, J.; Verano, M.; Brimmo, A.T.; Glia, A.; Qasaimeh, M.A.; Chen, P.; Aleman, J.O.; Chen, W. An integrated adipose-tissue-on-chip nanoplasmonic biosensing platform for investigating obesity-associated inflammation. Lab Chip 2018, 18, 3550-3560. [CrossRef]

96. Wang, Y.; Yuan, W.; Kimber, M.J.; Lu, M.; Dong, L. Rapid Differentiation of Host and Parasitic Exosome Vesicles Using Microfluidic Photonic Crystal Biosensor. ACS Sens. 2018, 3, 1616-1621. [CrossRef]

97. Choi, C.J.; Block, I.D.; Bole, B.; Dralle, D.; Cunningham, B.T. Label-Free Photonic Crystal Biosensor Integrated Microfluidic Chip for Determination of Kinetic Reaction Rate Constants. IEEE Sens. J. 2009, 9, 1697-1704. [CrossRef]

98. Choi, C.J.; Cunningham, B.T. A 96-well microplate incorporating a replica molded microfluidic network integrated with photonic crystal biosensors for high throughput kinetic biomolecular interaction analysis. Lab Chip 2007, 7, 550. [CrossRef]

99. Lin, Y.-C.; Hsieh, W.-H.; Chau, L.-K.; Chang, G.-E. Intensity-detection-based guided-mode-resonance optofluidic biosensing system for rapid, low-cost, label-free detection. Sens. Actuators B Chem. 2017, 250, 659-666. [CrossRef]

100. Tsai, M.-Z.; Hsiung, C.-T.; Cheng-Sheng, H.; Huang, C.-S.; Hsu, H.-Y.; Hsieh, P.-Y. Real-time CRP detection from whole blood using micropost-embedded microfluidic chip incorporated with label-free biosensor. Analyst 2018, 143, 503-510. [CrossRef] [PubMed]

101. Foudeh, A.M.; Didar, T.F.; Veres, T.; Tabrizian, M. Microfluidic designs and techniques using lab-on-a-chip devices for pathogen detection for point-of-care diagnostics. Lab Chip 2012, 12, 3249-3266. [CrossRef]

102. Kumar, S.; Cherukulappurath, S.; Johnson, T.W.; Oh, S.-H. Millimeter-Sized Suspended Plasmonic Nanohole Arrays for Surface-Tension-Driven Flow-Through SERS. Chem. Mater. 2014, 26, 6523-6530. [CrossRef] [PubMed]

103. Kong, X.; Xi, Y.; Leduff, P.; Li, E.; Liu, Y.; Cheng, L.-J.; Rorrer, G.L.; Tan, H.; Wang, A.X. Optofluidic sensing from inkjet-printed droplets: The enormous enhancement by evaporation-induced spontaneous flow on photonic crystal biosilica. Nanoscale 2016, 8, 17285-17294. [CrossRef] [PubMed]

104. Grilli, S.; Miccio, L.; Gennari, O.; Coppola, S.; Vespini, V.; Battista, L.; Orlando, P.; Ferraro, P. Active accumulation of very diluted biomolecules by nano-dispensing for easy detection below the femtomolar range. Nat. Commun. 2014, 5, 5314. [CrossRef] [PubMed]

105. O'Farrell, B. Evolution in Lateral Flow-Based Immunoassay Systems. In Lateral Flow Immunoassay; Humana Press: Totowa, NJ, USA, 2009; pp. 1-33.

106. Christodouleas, D.C.; Kaur, B.; Chorti, P. From Point-of-Care Testing to eHealth Diagnostic Devices (eDiagnostics). ACS Central Sci. 2018, 4, 1600-1616. [CrossRef]

107. Sharma, S.; Zapatero-Rodríguez, J.; Estrela, P.; O'Kennedy, R.J. Point-of-Care Diagnostics in Low Resource Settings: Present Status and Future Role of Microfluidics. Biosensors 2015, 5, 577-601. [CrossRef]

108. Clarke, O.J.R.; Goodall, B.L.; Hui, H.P.; Vats, N.; Brosseau, C.L. Development of a SERS-Based Rapid Vertical Flow Assay for Point-of-Care Diagnostics. Anal. Chem. 2017, 89, 1405-1410. [CrossRef]

109. Chen, P.; Gates-Hollingsworth, M.; Pandit, S.; Park, A.; Montgomery, D.; Aucoin, D.; Gu, J.; Zenhausern, F. Paper-based Vertical Flow Immunoassay (VFI) for detection of bio-threat pathogens. Talanta 2019, 191, 81-88. [CrossRef]

110. Joung, H.-A.; Ballard, Z.S.; Ma, A.; Tseng, D.K.; Teshome, H.; Burakowski, S.; Garner, O.B.; Di Carlo, D.; Ozcan, A. Paper-based multiplexed vertical flow assay for point-of-care testing. Lab Chip 2019, 19, 1027-1034. [CrossRef]

111. Isakadze, N.; Martin, S.S. How useful is the smartwatch ECG? Trends Cardiovasc. Med. 2020, 30, 442-448. [CrossRef] [PubMed]

112. Wang, P.; Kricka, L.J. Current and Emerging Trends in Point-of-Care Technology and Strategies for Clinical Validation and Implementation. Clin. Chem. 2018, 64, 1439-1452. [CrossRef] [PubMed] 
113. Ravishankar, D. DNA Sequencing Shift to Point-of-Care Testing. 2014. Available online: https://healthcarein-europe.com/07.08.2014 (accessed on 12 December 2020).

114. Dou, M.; Dominguez, D.C.; Li, X.; Sanchez, J.; Scott, G. A Versatile PDMS/Paper Hybrid Microfluidic Platform for Sensitive Infectious Disease Diagnosis. Anal. Chem. 2014, 86, 7978-7986. [CrossRef] [PubMed]

115. Chen, A.; Wang, R.; Bever, C.R.S.; Xing, S.; Hammock, B.D.; Pan, T. Smartphone-interfaced lab-on-a-chip devices for field-deployable enzyme-linked immunosorbent assay. Biomicrofluidics 2014, 8, 064101. [CrossRef]

116. Puiu, M.; Gurban, A.-M.; Rotariu, L.; Brajnicov, S.; Viespe, C.; Bala, C. Enhanced Sensitive Love Wave Surface Acoustic Wave Sensor Designed for Immunoassay Formats. Sensors 2015, 15, 10511-10525. [CrossRef]

117. Sonato, A.; Agostini, M.; Ruffato, G.; Gazzola, E.; Liuni, D.; Greco, G.; Travagliati, M.; Cecchini, M.; Romanato, F. A surface acoustic wave (SAW)-enhanced grating-coupling phase-interrogation surface plasmon resonance (SPR) microfluidic biosensor. Lab Chip 2016, 16, 1224-1233. [CrossRef]

118. He, J.; Boegli, M.; Bruzas, I.; Lum, W.; Sagle, L.B. Patterned Plasmonic Nanoparticle Arrays for Microfluidic and Multiplexed Biological Assays. Anal. Chem. 2015, 87, 11407-11414. [CrossRef]

119. Jahns, S.; Bräu, M.; Meyer, B.-O.; Karrock, T.; Gutekunst, S.B.; Blohm, L.; Selhuber-Unkel, C.; Buhmann, R.; Nazirizadeh, Y.; Gerken, M. Handheld imaging photonic crystal biosensor for multiplexed, label-free protein detection. Biomed. Opt. Express 2015, 6, 3724-3736. [CrossRef]

120. Yap, L.W.; Chen, H.; Gao, Y.; Petkovic, K.; Liang, Y.; Si, K.J.; Wang, H.; Tang, Z.; Zhu, Y.; Cheng, W. Bifunctional plasmonic-magnetic particles for an enhanced microfluidic SERS immunoassay. Nanoscale 2017, 9, 7822-7829. [CrossRef]

121. Jiang, L.Y. Biomedical Diagnostics at Point-of-Care 2019-2029_ Technologies, Applications, ForecastsIDTechEx.pdf. IDTechEx, 16 January 2019. Available online: https://www.idtechex.com/en/researchreport/biomedical-diagnostics-at-point-of-care-2019-2029-technologies-applications-forecasts/622 (accessed on 12 December 2020).

122. Markets and Markets. Point of Care Diagnostics Market by Product (Glucose, Infectious Disease (Hepatitis C, Influenza, Respiratory), Coagulation), Platform (Microfluidics, Immunoassays), Mode (Prescription \& OTC), End-User (Hospitals, Home Care)—Global Forecast to 2024. 2019. Available online: https: //www.marketsandmarkets.com/Market-Reports/point-of-care-diagnostic-market-106829185.html (accessed on 12 December 2020).

123. Data, R.A. Point of Care (PoC) Diagnostics Market to Reach USD 50.51 Billion By 2026 | Reports and Data 2019. June 12, 2019 13:02 ET | Source: Reports And Data. Available online: https://www.globenewswire.com/news-release/2019/06/12/1867809/0/en/Point-of-CarePoC-Diagnostics-Market-To-Reach-USD-50-51-Billion-By-2026-Reports-And-Data.html (accessed on 12 December 2020).

124. Research, G.V. (2019, Grand View Research). Point of Care Diagnostics/Testing Market Size, Share \& Trends Analysis Report by Product (Glucose, Blood Gas/Electrolytes, Cancer Marker), By End Use (Clinic, Hospital), And Segment Forecasts, 2019-2025. Mar, 2019. Available online: https://www.radiantinsights.com/research/ point-of-care-diagnostics-testing-market (accessed on 12 December 2020).

Publisher's Note: MDPI stays neutral with regard to jurisdictional claims in published maps and institutional affiliations.

(C) 2020 by the authors. Licensee MDPI, Basel, Switzerland. This article is an open access article distributed under the terms and conditions of the Creative Commons Attribution (CC BY) license (http://creativecommons.org/licenses/by/4.0/). 